Review

\title{
Specialized questioning techniques and their use in conservation: A review of available tools, with a focus on methodological advances
}

\author{
Jacopo Cerri ${ }^{\mathrm{a}, *}$, Elizabeth Oneita Davis ${ }^{\mathrm{b}}$, Diogo Veríssimo ${ }^{\mathrm{b}, \mathrm{c}}$, Jenny Anne Glikman ${ }^{\mathrm{b}, \mathrm{d}}$ \\ ${ }^{a}$ Faculty of Mathematics, Natural Sciences and Information Technologies, University of Primorska, Glagoljaška 8, 6000 Koper, Slovenia \\ ${ }^{\mathrm{b}}$ San Diego Zoo Institute for Conservation Research, Escondido, CA, USA \\ ${ }^{\mathrm{c}}$ Department of Zoology, University of Oxford, Oxford, UK \\ ${ }^{\mathrm{d}}$ Instituto de Estudios Sociales Avanzados (IESA-CSIC), Campo Santo de los Mártires 7, Córdoba, Spain
}

\section{A R T I C L E I N F O}

\section{Keywords:}

Sensitive

Specialized questioning techniques

Surveys

Questionnaire

Noncompliance

Privacy

\begin{abstract}
A B S T R A C T
Conservationists measuring noncompliance with measures limiting the exploitation of natural resources often ask sensitive questions. However, respondents may distort their answers due to the risk of sanctions, taboos or social norms. Specialized Questioning Techniques (SQTs) can encourage honest answering through protecting respondent's privacy by design. This study provides a complete overview of the main SQTs, as well as their most recent advances. We performed a scoping review of existing SQTs, starting with those covered in Nuno and St. John (2015). We covered techniques which advanced over the last few years $(n=14)$, and included techniques that have never been explained in a conservation context before $(n=2)$, or that were invented after $2015(n=4)$, like the parallel model, the pair method, the list method and the person count technique. We explained each technique with real, or hypothetical, examples and also discussed advantages and limitations, emphasizing the need to understand the context where they are applied and to imagine the potential repercussions of SQTs, to protect both respondents and their communities. SQTs developed impressively over the last few years, and many different techniques are available to elicit sensitive behaviors with implications for conservation. This research offers a summary to conservationists and practitioners who want to approach this topic and integrate them in their work.
\end{abstract}

\section{Introduction}

Conservation research often deals with human behaviors that are illegal and/or subjected to social desirability (Solomon et al., 2015; St. John et al., 2015). Conservationists are often interacting with and/or studying systems in which people are committing illegal acts, where people have expectations about others' evaluation of their own conservation-related behavior and/or where some conservation-related issues are taboo (Krumpal, 2013).

As a result, conservationists who attempt to study the prevalence and drivers of such behaviors through questionnaire surveys may find that data gathered from respondents are biased (e.g. Davis et al., 2019; St. John et al., 2010; St. John et al., 2015). The keystone of this bias often lies in the way answers are collected, usually direct questioning, and in its implications for perceived privacy protection. When respondents are recruited "in the field" (including in person and online), they are (ideally) assured that their privacy is protected by researchers' commitment to the confidentiality of the findings. However, this commitment is often not enough to outweigh the potential costs connected with revealing deviant and/or illegal behavior and, even in confidential direct answers, respondents might feel their privacy is not adequately protected (Brittain et al., 2020). This includes online surveys that are "removed" from direct human interaction; increasingly, individuals are aware, and wary of, breaches in data privacy (Baruh et al., 2017). Moreover, in contexts characterized by human rights abuses, where local authorities may sift through researchers' data (Russo and Strazzari, 2020), direct answers could jeopardize both researchers and participants, especially for studies exploring deviant behaviors.

Specialized Questioning Techniques (SQTs) have been proposed as a way to overcome these issues, through anonymizing answers by design. Over the last 20 years, SQTs have been increasingly applied to understand and monitor human behavior in conservation, especially the Unmatched Count Technique (UCT) and the Randomized Response Technique (RRT) (e.g. Nuno et al., 2013; Solomon et al., 2007). This

\footnotetext{
* Corresponding author.

E-mail address: jacopo.cerri@famnit.upr.si (J. Cerri).
} 
increase in the use of SQT were discussed in a systematic review in 2015 (Nuno and St John, 2015), which provided researchers with a broad overview of existing methods; however, the authors noted that SQTs were still under-utilized in studies designed to accurately understand human behavior. Following this review, conservationists, albeit still adopting classical designs of some SQTs, like the RRT or the UCT, became increasingly aware of their potential limitations (Davis et al., 2019; Hinsley et al., 2019).

Many things have changed since 2015, in the field of SQTs. There has been a notable increase in the use of the "classical" SQTs of RRT and UCT (e.g. Cerri et al., 2017; Cerri et al., 2018a; Chang et al., 2018; Davis et al., 2019; Davis et al., 2020b; Hinsley et al., 2017; Ibbett et al., 2019), with corresponding advancements in understanding how useful these methods are in varying contexts and for varying behaviors. This is largely the result of continually increasing recognition of the importance of understanding and measuring conservation-related human behavior (Bennett et al., 2017), as well as deviant behavior in general (Gino and Ariely, 2016); for example, SQTs are now seen as a means to accurately measure prevalence to inform impact evaluations of behavior change campaigns (e.g. Davis et al., 2020b; Veríssimo et al., 2020). Ongoing global digitalization offered new fields of application for SQTs, and social scientists started designing methods suitable for Internet users, e.g. the use of UCTs to investigate CITES compliance by orchid traders and consumers (Hinsley et al., 2017). However, researchers became increasingly aware that SQTs are cognitively demanding, can suffer from large estimation errors (e.g. Hinsley et al., 2019; Davis et al., 2020a, 2020b), do not always remove response bias, and in many cases, do not allow researchers to link behaviors to their antecedents (e.g. Chuang et al., 2019).

Despite these issues, it is undoubtedly important that researchers utilize methods that will ensure they gather the most accurate estimations of behaviors that can threaten natural resources. By doing so, researchers can more effectively advise on conservation management priorities and where best to allocate money and time, while also providing robust, evidence-based baselines that conservation interventions can be evaluated against.

To understand and illuminate potential opportunities for expansion into more effective SQTs in conservation, we reviewed the available social science and statistical literature about advances in SQTs since Nuno and St John's (2015) review. Here, we investigate published critiques and methodological analyses of each technique, and discuss the main challenges that SQTs face. Our overall aim for this study is to: (i) explain existing SQTs, (ii) summarize the most recent advances in existing SQTs and (iii) introduce novel SQTs that appeared after 2015, providing practical examples to practitioners and researchers working in conservation, and illuminating potential limitations and strengths of these methods.

\section{Methods}

We conducted a scoping review of SQT. Scoping reviews differ from systematic reviews, as their main goal is not to collect, sieve, summarize and compare available studies about a certain topic. Rather, they produce a narrative presentation of available research in a certain field, by mapping available knowledge from a many different sources. In doing so, scoping reviews can assess the extent of available research, the way it has been conducted and also identify research gaps (Munn et al., 2018). The adoption of a scoping review was motivated by the fact that, when replicating the query adopted in 2015 (Nuno and St John, 2015) on ISI and Scopus, we found more than 9000 studies, often not directly related to deviant or illegal behavior. Most of these studies were adopting questionnaires for diverse reasons, and only marginally mentioned social desirability or response bias in the discussion. The effectiveness of the original query was probably affected by growth in indexed scientific publications in the English language, which almost doubled since 2014 (Bornmann and Mutz, 2015).
Our scoping review was nevertheless based on a structured search protocol. First, starting from Nuno and St John (2015), we identified 11 SQTs, each one characterized by one, or more, seminal studies: the randomized response technique (Greenberg, Abul-Ela, Simmons, \& Horovitz 1969; Kuk, 1990; Warner, 1965), the unmatched count technique (UCT, also known as "list experiment", Droitcour et al., 2004), the item sum technique (Trappmann et al., 2014) the nominative technique (Miller, 1985), the grouped-answer method (also known as the "threecard method", Droitcour and Larson, 2002), the crosswise model (Yu et al., 2008), the triangular model (Yu et al., 2008), the diagonal model (Groenitz, 2014), the hidden sensitivity model (Tian et al., 2007), the negative question method (Esponda and Guerrero, 2009), and the bean method (Lau et al., 2011). For each one of these 11 SQTs we read those studies that had proposed them for the first time, and then we searched on Google Scholar for those studies published after 2015, which cited them. For the more widely-used SQTs of RRT and UCT we confined our search to conservation-specific studies. We operationalized our search on Google Scholar, to ensure a better coverage of the gray literature. To increase the effectiveness of our strategy we also searched for those studies that cited two major reviews about SQTs in conservation (Hinsley et al., 2019; Nuno and St John, 2015).

In addition, we also considered SQTs that appeared after 2015 or were not covered in Nuno and St John (2015), and which we had encountered during our on-line search of related articles: the person count technique, the parallel model, the list method, the pair method, the ballot box method and endorsement experiments.

We grouped SQTs based on differences in their practical implementation (e.g. methods using a randomizing device), rather than according to differences in the statistical estimation of parameters (e.g. the crosswise model can be regarded as a variant of the RRT). We deem this classification to be more helpful for conservation scientists, to better grasp the underlying idea behind the various SQTs and to imagine their application in various settings.

\section{Results}

In terms of their privacy protection mechanism, we found 11 main groups of techniques (Table 1, Fig. 1). The nominative technique, the grouped-answer method, the diagonal model, the hidden sensitivity model, negative questions and the bean method did not receive any significant advance in their practical implementation, since 2015, although some of these methods have now begun to be adopted by conservation researchers (e.g. the bean method, Cerri et al., 2018a; Jones et al., 2020). Since 2015, we found 4 invented new SQTs and 14 advances of existing techniques (Table 1). Below we briefly explain these methods. In the following lines, we aim to provide an introduction to the three main types of SQTs, which were advanced since 2015. We will discuss the Randomized Response Technique (3.1), the Unmatched Count Technique (and its quantitative counterpart, the item-sum technique) (3.2), and two non-randomized techniques: the crosswise and the triangular model (3.3). Following this, we will describe SQTs that were not included in previous reviews (3.4), and new SQTs we identified in our literature search (3.5).

\subsection{The randomized response technique}

The Randomized Response Technique (RRT) introduces some noise, with a known probability distribution, to mask individual answers (Nuno and St John, 2015). Various statistical approaches are then adopted to handle this noise, estimate behavioral prevalence and also obtain likelihood functions to model individual covariates (Cruyff et al., 2016b). Noise can come from a randomizing device or from one, or more, non-sensitive question. Of course, the higher the amount of noise, the higher the level of privacy protection, but at the cost of the statistical efficiency of the estimator. It is possible to play with people's misperception of probabilities to increase the efficiency of the randomization. 
Table 1

Groups of SQTs that we identified, classified on the basis of their privacyprotection mechanism. Advances in existing techniques, as well as new SQTs are indicated as "new!".

\begin{tabular}{|c|c|c|c|c|}
\hline Group & $\begin{array}{l}\text { Privacy } \\
\text { protection } \\
\text { mechanism }\end{array}$ & $\begin{array}{l}\text { Main types, new } \\
\text { versions and } \\
\text { seminal studies }\end{array}$ & $\begin{array}{l}\text { Type of } \\
\text { outcomes }\end{array}$ & $\begin{array}{l}\text { Individual } \\
\text { covariates }\end{array}$ \\
\hline 1 & $\begin{array}{l}\text { Noise with a } \\
\text { known } \\
\text { distribution is } \\
\text { added to } \\
\text { individual } \\
\text { answers, usually } \\
\text { through a } \\
\text { randomizing } \\
\text { device (e.g. a die, } \\
\text { a deck of cards). } \\
\text { Privacy is } \\
\text { protected by } \\
\text { adding noise at } \\
\text { the individual } \\
\text { level, } \\
\text { respondents } \\
\text { should feel } \\
\text { protected and } \\
\text { provide honest } \\
\text { answers. }\end{array}$ & $\begin{array}{l}\text { Forced response } \\
\text { RRT (Boruch, 1971) } \\
\text { Multidimensional } \\
\text { RRT (Cruyff et al., } \\
\text { 2016a) new! } \\
\text { Quantitative RRT ( } \\
\text { Cao et al., 2018) } \\
\text { new! } \\
\text { Unrelated question } \\
\text { RRT (Greenberg, } \\
\text { 1969) } \\
\text { Optional unrelated } \\
\text { question (Chhabra } \\
\text { et al., 2016) new! } \\
\text { Cheater detection } \\
\text { model (Schröter } \\
\text { et al., 2016) new! } \\
\text { RRT-crosswise } \\
\text { design (Tu and } \\
\text { Hsieh, 2017) new! }\end{array}$ & $\begin{array}{l}\text { Binary } \\
\text { Ordinal } \\
\text { scales } \\
\text { Discrete } \\
\text { counts } \\
\text { Multinomial } \\
\text { scales }\end{array}$ & Yes \\
\hline & & $\begin{array}{l}\text { Mirrored design } \\
\text { RRT (Warner, 1965) }\end{array}$ & & \\
\hline & & $\begin{array}{l}\text { Disguised response } \\
\text { RRT (Kuk, 1990) }\end{array}$ & & \\
\hline 2 & $\begin{array}{l}\text { Respondents are } \\
\text { asked to provide } \\
\text { an overall answer } \\
\text { about a set of } \\
\text { behaviors, } \\
\text { including } \\
\text { sensitive and } \\
\text { non-sensitive } \\
\text { ones. They might } \\
\text { indicate how } \\
\text { many of these } \\
\text { behaviors apply } \\
\text { to them (UCT), or } \\
\text { summing the } \\
\text { frequencies of } \\
\text { individual } \\
\text { answers (IST). } \\
\text { The difference } \\
\text { between groups } \\
\text { estimates the } \\
\text { frequency of the } \\
\text { behavior of } \\
\text { interest. Privacy } \\
\text { is protected by } \\
\text { the fact that } \\
\text { respondents } \\
\text { provide an } \\
\text { overall answer } \\
\text { about a set of } \\
4-10 \text { behaviors. }\end{array}$ & $\begin{array}{l}\text { Item count } \\
\text { technique ( } \\
\text { Droitcour et al., } \\
\text { 2004). } \\
\text { Double list UCT ( } \\
\text { Glynn, 2013) } \\
\text { Single-sample count } \\
\text { UCT (Petróczi et al., } \\
\text { 2011) } \\
\text { Longitudinal UCT ( } \\
\text { Gaia and Al Baghal, } \\
\text { 2019) new! } \\
\text { Negative binomial/ } \\
\text { Poisson UCT (Tian } \\
\text { et al., 2017) new! } \\
\text { Poisson-Poisson } \\
\text { UCT (Liu et al., } \\
\text { 2019) new! } \\
\text { Item sum technique } \\
\text { (IST, Trappmann } \\
\text { et al., 2014) } \\
\text { Double list IST ( } \\
\text { Krumpal et al., } \\
\text { 2018) new! }\end{array}$ & $\begin{array}{l}\text { Binary (UCT) } \\
\text { Discrete } \\
\text { counts (ICT) }\end{array}$ & Yes \\
\hline 3 & $\begin{array}{l}\text { Respondents } \\
\text { provide a } \\
\text { conjoint answers } \\
\text { to two, or more, } \\
\text { questions. These } \\
\text { include the } \\
\text { sensitive } \\
\text { question of } \\
\text { interest and one, } \\
\text { or more, non- } \\
\text { sensitive } \\
\text { questions whose } \\
\text { prevalence in the }\end{array}$ & $\begin{array}{l}\text { Crosswise model ( } \\
\text { Yu et al., 2008) } \\
\text { Extended Crosswise } \\
\text { Model (Heck et al., } \\
\text { 2018) new! } \\
\text { RRT-crosswise } \\
\text { design (Tu and } \\
\text { Hsieh, 2017) new! } \\
\text { Triangular model ( } \\
\text { Yu et al., 2008) } \\
\text { Dual non- } \\
\text { randomized }\end{array}$ & $\begin{array}{l}\text { Binary } \\
\text { Discrete } \\
\text { counts }\end{array}$ & Yes \\
\hline
\end{tabular}

Table 1 (continued)

\begin{tabular}{|c|c|c|c|c|}
\hline Group & $\begin{array}{l}\text { Privacy } \\
\text { protection } \\
\text { mechanism }\end{array}$ & $\begin{array}{l}\text { Main types, new } \\
\text { versions and } \\
\text { seminal studies }\end{array}$ & $\begin{array}{l}\text { Type of } \\
\text { outcomes }\end{array}$ & $\begin{array}{l}\text { Individual } \\
\text { covariates }\end{array}$ \\
\hline 4 & $\begin{array}{l}\text { population is } \\
\text { known. Privacy is } \\
\text { protected by the } \\
\text { fact that } \\
\text { respondents } \\
\text { provide a } \\
\text { conjoint answer } \\
\text { (e.g. in CM they } \\
\text { indicate if they } \\
\text { provided two } \\
\text { different answers } \\
\text { to the two } \\
\text { questions, or not) } \\
\text { and one of the } \\
\text { two questions is } \\
\text { sensitive. } \\
\text { Respondents are } \\
\text { allocated to two } \\
\text { groups, each one } \\
\text { containing three } \\
\text { blocks. The two } \\
\text { groups contain a } \\
\text { list with the one } \\
\text { sensitive and } \\
\text { various non- } \\
\text { sensitive } \\
\text { behaviors, which } \\
\text { are assigned at } \\
\text { random to the } \\
\text { three blocks, so } \\
\text { that Group1 and } \\
\text { Group2 have the } \\
\text { same overall } \\
\text { behaviors, but } \\
\text { coupled } \\
\text { differently. } \\
\text { Respondents } \\
\text { indicate only the } \\
\text { block (A, B or C) } \\
\text { to which they } \\
\text { belong, without } \\
\text { indicating their } \\
\text { real behavior. } \\
\text { Privacy is } \\
\text { protected } \\
\text { because } \\
\text { researchers do } \\
\text { not know which } \\
\text { is the behavior } \\
\text { practiced by } \\
\text { respondents. }\end{array}$ & $\begin{array}{l}\text { response (Wu and } \\
\text { Tang, 2016) new! } \\
\text { Alternating non- } \\
\text { randomized } \\
\text { response (Wu and } \\
\text { Tang, 2016) new! } \\
\text { Diagonal model ( } \\
\text { Groenitz, 2014) } \\
\text { Hidden sensitivity } \\
\text { model (Tian et al., } \\
\text { 2007) } \\
\text { Parallel model ( } \\
\text { Tian, 2014) new! } \\
\text { Grouped-answer } \\
\text { method (Droitcur \& } \\
\text { Larson, 2002) }\end{array}$ & Binary & No \\
\hline 5 & $\begin{array}{l}\text { Respondents are } \\
\text { asked questions } \\
\text { posed in a } \\
\text { negative } \\
\text { direction (e.g. 'I } \\
\text { did not fish ...), } \\
\text { so they do not } \\
\text { answer any } \\
\text { sensitive } \\
\text { question which } \\
\text { could jeopardize } \\
\text { them. }\end{array}$ & $\begin{array}{l}\text { Negative question ( } \\
\text { Esponda and } \\
\text { Guerrero, 2009) }\end{array}$ & $\begin{array}{l}\text { Binary } \\
\text { Ordinal } \\
\text { Multinomial }\end{array}$ & Yes \\
\hline 6 & $\begin{array}{l}\text { Respondents are } \\
\text { provided with } \\
\text { two jars of } \\
\text { multicolored } \\
\text { beans. They are } \\
\text { asked to move a } \\
\text { black bean from } \\
\text { the small to the } \\
\text { large jar, if the } \\
\text { answer to a } \\
\text { question is "no" }\end{array}$ & $\begin{array}{l}\text { Bean method (Lau } \\
\text { et al., 2011) }\end{array}$ & Binary & No \\
\hline
\end{tabular}


Table 1 (continued)

\begin{tabular}{|c|c|c|c|c|}
\hline Group & $\begin{array}{l}\text { Privacy } \\
\text { protection } \\
\text { mechanism }\end{array}$ & $\begin{array}{l}\text { Main types, new } \\
\text { versions and } \\
\text { seminal studies }\end{array}$ & $\begin{array}{l}\text { Type of } \\
\text { outcomes }\end{array}$ & $\begin{array}{l}\text { Individual } \\
\text { covariates }\end{array}$ \\
\hline & $\begin{array}{l}\text { and a bean of a } \\
\text { certain color, if } \\
\text { the answer to a } \\
\text { question is "yes". } \\
\text { After many } \\
\text { answers, beans } \\
\text { are counted. } \\
\text { Privacy is } \\
\text { protected } \\
\text { because (i) jars } \\
\text { have many } \\
\text { beans, so that the } \\
\text { movement of a } \\
\text { single bean goes } \\
\text { unnoticed, (ii) } \\
\text { jars are opened at } \\
\text { the end of the } \\
\text { study and (iii) } \\
\text { respondents are } \\
\text { not observed by } \\
\text { researchers, } \\
\text { when they move } \\
\text { beans. }\end{array}$ & & & \\
\hline 7 & $\begin{array}{l}\text { PM: respondents } \\
\text { answer the } \\
\text { sensitive } \\
\text { question and a } \\
\text { safe question, } \\
\text { picked from a } \\
\text { list. The two } \\
\text { answers are then } \\
\text { written down in a } \\
\text { random order } \\
\text { and privacy is } \\
\text { protected by } \\
\text { private } \\
\text { randomization } \\
\text { made by } \\
\text { respondents. }\end{array}$ & $\begin{array}{l}\text { List method ( } \\
\text { Lagerås and } \\
\text { Lindholm, 2020) } \\
\underline{\text { new! }}\end{array}$ & Multinomial & No \\
\hline 8 & $\begin{array}{l}\text { LM: respondent is } \\
\text { presented with a } \\
\text { list of options and } \\
\text { indicate if the } \\
\text { sensitive option } \\
\text { is on the list. } \\
\text { Each respondent } \\
\text { receives a } \\
\text { different list of } \\
\text { options, } \\
\text { extracted at } \\
\text { random. }\end{array}$ & $\begin{array}{l}\text { Pair method ( } \\
\text { Lagerås and } \\
\text { Lindholm, 2020) } \\
\underline{\text { new! }}\end{array}$ & Multinomial & No \\
\hline 9 & $\begin{array}{l}\text { Respondents } \\
\text { indicate how } \\
\text { many people in } \\
\text { their social } \\
\text { network engage } \\
\text { into a sensitive } \\
\text { behavior. Then, } \\
\text { one of reported } \\
\text { people is picked } \\
\text { at random and } \\
\text { are asked how } \\
\text { many people they } \\
\text { believe to know } \\
\text { about their } \\
\text { friend's behavior } \\
\text { (NT). } \\
\text { Alternatively, } \\
\text { they are split in a } \\
\text { control and a } \\
\text { treatment group } \\
\text { (PCT). In the } \\
\text { treatment group, } \\
\text { respondents are }\end{array}$ & $\begin{array}{l}\text { Nominative } \\
\text { technique (Miller, } \\
\text { 1985) } \\
\text { Person count } \\
\text { technique (Wolter, } \\
\text { 2019) new! }\end{array}$ & $\begin{array}{l}\text { Discrete } \\
\text { counts }\end{array}$ & No \\
\hline
\end{tabular}

Table 1 (continued)

\begin{tabular}{|c|c|c|c|c|}
\hline Group & $\begin{array}{l}\text { Privacy } \\
\text { protection } \\
\text { mechanism }\end{array}$ & $\begin{array}{l}\text { Main types, new } \\
\text { versions and } \\
\text { seminal studies }\end{array}$ & $\begin{array}{l}\text { Type of } \\
\text { outcomes }\end{array}$ & $\begin{array}{l}\text { Individual } \\
\text { covariates }\end{array}$ \\
\hline 10 & $\begin{array}{l}\text { asked to add } \\
\text { themselves to the } \\
\text { number of } \\
\text { indicated people. } \\
\text { Privacy is } \\
\text { protected } \\
\text { because } \\
\text { researchers do } \\
\text { not know the real } \\
\text { number of people } \\
\text { nominated by } \\
\text { respondents. } \\
\text { Respondents are } \\
\text { provided with } \\
\text { voting tokens, } \\
\text { with a color and a } \\
\text { number } \\
\text { corresponding to } \\
\text { the answers to } \\
\text { the various } \\
\text { questions. An } \\
\text { enumerator then } \\
\text { explains the } \\
\text { technique and } \\
\text { reads the } \\
\text { questions. } \\
\text { Respondents put } \\
\text { their tokens sheet } \\
\text { into a sealed box, } \\
\text { which is opened } \\
\text { at the end of the } \\
\text { study. Privacy is } \\
\text { protected } \\
\text { because the urn is } \\
\text { opened well after } \\
\text { the interview and } \\
\text { it is impossible to } \\
\text { trace back } \\
\text { individual } \\
\text { answers. }\end{array}$ & $\begin{array}{l}\text { Ballot box method ( } \\
\text { Gregson et al., } \\
\text { 2002) }\end{array}$ & $\begin{array}{l}\text { Binary } \\
\text { Ordered } \\
\text { scales } \\
\text { Discrete } \\
\text { counts }\end{array}$ & No \\
\hline 11 & $\begin{array}{l}\text { Respondents are } \\
\text { randomly } \\
\text { allocated to a } \\
\text { control and a } \\
\text { treatment } \\
\text { condition. The } \\
\text { control condition } \\
\text { illustrates a } \\
\text { certain issue (e.g. } \\
\text { a policy), while } \\
\text { treatment } \\
\text { condition } \\
\text { highlights a } \\
\text { certain aspect of } \\
\text { interest of that } \\
\text { issue (e.g. policy } \\
\text { impacts over } \\
\text { wildlife trade). } \\
\text { Respondents } \\
\text { express their } \\
\text { approval of the } \\
\text { subject } \\
\text { described, } \\
\text { ignoring } \\
\text { respondents in } \\
\text { the other } \\
\text { condition. The } \\
\text { difference in } \\
\text { scores between } \\
\text { the two groups } \\
\text { reflects the extent } \\
\text { to which a } \\
\text { certain issue is } \\
\text { endorsed by }\end{array}$ & $\begin{array}{l}\text { Endorsement } \\
\text { experiments (Blair } \\
\text { et al., 2014; } \\
\text { Rosenfeld, Imai, \& } \\
\text { Shapiro 2015). }\end{array}$ & $\begin{array}{l}\text { Ordered } \\
\text { scales } \\
\text { (usually } \\
\text { bipolar) }\end{array}$ & No \\
\hline
\end{tabular}


Table 1 (continued)

\begin{tabular}{|c|c|c|c|c|}
\hline Group & $\begin{array}{l}\text { Privacy } \\
\text { protection } \\
\text { mechanism }\end{array}$ & $\begin{array}{l}\text { Main types, new } \\
\text { versions and } \\
\text { seminal studies }\end{array}$ & $\begin{array}{l}\text { Type of } \\
\text { outcomes }\end{array}$ & $\begin{array}{l}\text { Individual } \\
\text { covariates }\end{array}$ \\
\hline & $\begin{array}{l}\text { respondents. } \\
\text { Privacy is not } \\
\text { protected, but } \\
\text { framing might } \\
\text { make } \\
\text { respondents' } \\
\text { unaware of } \\
\text { questions' } \\
\text { sensitivity, as a } \\
\text { certain question } \\
\text { could appear } \\
\text { sensitive only if } \\
\text { compared to } \\
\text { other questions } \\
\text { in a survey. }\end{array}$ & & & \\
\hline
\end{tabular}

In terms of their practical implementation, there are four major approaches to the RRT, but all of them assume that respondents are left alone when answering the question. Since 2015, there have also been 7 new RRT advances proposed. Below, we discuss both pre-existing types of RRT as well as new advances.

\subsubsection{Pre-existing RRTs}

In the forced response design (Boruch, 1971), the most common RRT in conservation studies (e.g. Cerri et al., 2017; Davis et al., 2019; Santangeli et al., 2016; St. John et al., 2015), respondents use the randomizing device to make it impossible for researchers to know which options were selected in a multi-option question, or which numerical answers were provided. For example, respondents may be given a traditional six-sided die. If respondents roll 1 , they are asked to give a forced response of " $n$ " to the question. If they roll 6 , they must give a forced response of "yes". If they roll 2, 3, 4, 5 then they can answer truthfully (Fig. 2). The biggest advantage of the forced-response RRT lies in the fact that its only assumption is about respondents' compliance with instructions, and its statistical efficiency is higher than the other RRTs. On the other hand, it requires the use of a randomizing device, with three main limitations: (i) respondents should understand how to use it, (ii) respondents should be familiar with that particular device, to understand how it will protect their privacy, (iii) respondents should trust the randomizing device (e.g. dice may not be suitable for use in societies where gambling is taboo) and (iv) the context where the questionnaire is administered should be suitable for using the randomizing device (e.g. without a table a die cannot be rolled).

In the unrelated question design (Greenberg, Abul-Ela, Simmons, \& Horovitz 1969), the randomizing devices allocates respondents to one of two questions, with identical response options (e.g. Yes/No). Privacy is

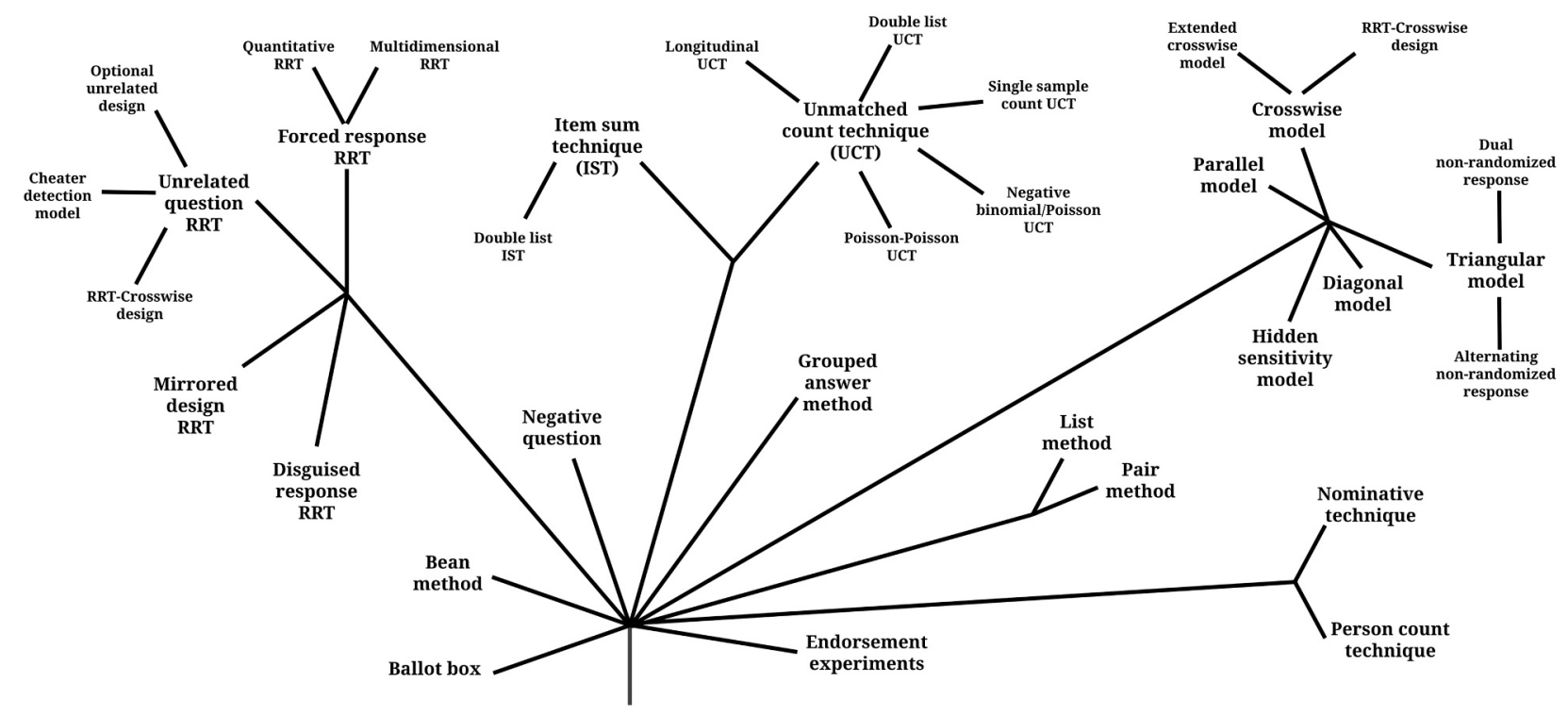

Fig. 1. Groups of SQTs, single techniques and their advances.

\begin{tabular}{|c|c|c|}
\hline Instructions & Remember! & Question \\
\hline $\begin{array}{l}\text { Before answering to the } \\
\text { question, please, roll the } \\
\text { die and check the } \\
\text { number that appeared } \\
\text { on the top. }\end{array}$ & $\begin{array}{l}\text { If the number is ... } \\
1=\text { answer "Yes" } \\
6 \text { = answer "No" }\end{array}$ & $\begin{array}{l}\text { Over the last } 12 \text { months, } \\
\text { did you go fishing } \\
\text { without having a valid } \\
\text { fishing permit? }\end{array}$ \\
\hline
\end{tabular}

Fig. 2. An example instruction card for the forced-response RRT, containing a case study about illegal fishing (Cerri et al., 2018a). Respondents are provided with a 6-faces die, instructions and the question. The die must be rolled before answering and respondents must not reveal the outcome of die roll. Respondents could record their answers on a self-administered questionnaire (like in this example) or answer to an enumerator. 
therefore protected because it is impossible to know which question respondents were allocated to (e.g. Lee et al., 2017). One of the two questions is the sensitive question of interest, while the other is a nonsensitive question, whose prevalence in the target population is known (Fig. 3). This technique therefore grants greater privacy than forceresponse RRT, which may increase respondent compliance; however, it suffers from the same limitations as forced response RRT.

In the mirrored question design (derived from the indirect questioning mode, Warner, 1965), respondents are asked one of two mirrored sensitive questions/statements, according to probability (Blair et al., 2015). Like in the unrelated question design, here the randomizer allocates respondents to one of two conditions, making it impossible to understand to which question respondents were allocated (Fig. 4). As with the unrelated question technique, the respondent has greater privacy and may be more likely to comply, but the technique has the same limitations of implementation as in the forced response RRT.

In the disguised response design (Kuk, 1990), respondents never need to state "true/yes" or "false/no" to the interviewer. Instead, they are given two decks, which correspond to the real answer of respondents (one deck for "true-yes" and one deck for "true-no") with different proportions of colored cards, corresponding to "stated" yes/no. For example, Chang et al. (2018), in a study investigating bird hunting in China provided respondents with two decks with 15 cards each, one for the real "yes" and one for the real "no" answer. The "yes deck" had $80 \%$ red and $20 \%$ black cards, while the "no deck" contained $20 \%$ red and $80 \%$ black cards. Red cards corresponded to a "yes" response and black card with a "no" response. Respondents were asked to: ( $i$ ) draw a card from the deck corresponding to their true answer (e.g. from the "yes" deck if they really engaged in the behavior), (ii) not reveal which deck it is from, (iii) report the card's color, (iv) put back the card into the deck and ( $v$ ) shuffle the deck (Fig. 5). In the disguised response the privacy is protected by the fact that researchers do not know from which deck respondents drew the card. Chang et al. (2018) found that respondents were more likely to believe that disguised response gave them anonymity, compared to the forced-response. This indicates that disguised response may be effective at increasing respondents' comfort and therefore their compliance with instructions, compared to other RRTs.

\subsubsection{Advances in RRTs}

The quantitative RRT, for Poisson-distributed count data (Cao et al., 2018) follows the same method as the forced response (Boruch, 1971), but the response is a count variable. A sealed vessel with colored balls can be used as a randomizing device. Balls have a number from a known Poisson distribution. Respondents draw a ball and, based on its color, report their count answer or the number on the ball (Fig. 6). Compared to additive or multiplicative RRT (Eichhorn and Hayre, 1983; Pollock and Bek, 1976), the advantage of this approach lies in the fact that respondents do not have to sum or multiply quantities, thus reducing their cognitive load.

The multidimensional forced-response RRT (Cruyff et al., 2016a) is based on two nested forced-response questions, with both a 12 -faced and a 6-faced die used as the randomizing device. The first question estimates whether respondents engaged in the target behavior, while the second question quantifies its frequency (Fig. 7). The multidimensional design (i.e. whether the behavior occurred, and how frequently) is more efficient than unidimensional forced-response designs, as it can detect and account for noncompliance with instructions, and it can be adapted for the estimation of multinomial outcomes (Cerri et al., 2018b). However, the adoption of two consecutive forced-responses, raises some doubts about its cognitive load and its practical application in many conservation settings, especially those characterized by low levels of literacy. It is worth noting that approaches such as to detect and account for non-compliance in unidimensional forced-response RRT have also been proposed (Blair et al., 2015).

With respect to the unrelated question design (Greenberg et al., 1969), as a certain question might be sensitive for one respondent, but not for another, the optional unrelated question design RRT was invented. Respondents are given the option of using a randomization device to answer a question about a sensitive behavior, or to simply answer the question directly if they believe that it is not sensitive (Fig. 8). If respondents are allocated to question $1_{\text {sensitive }}$ and believe the topic not to be sensitive, they can just answer question 2 sensitive directly. Respondents are given this option through an initial randomization device; thus, the researcher does not know whether the respondent has chosen to use the second randomization device or not. This technique ensures the accurate estimation of target behaviors, even on an ordered scale, while obtaining an estimation of their perceived sensitivity (Arnab and Rueda, 2016). While this method was evaluated from a mathematical standpoint, there has to date been only one application in a real scenario (sexual abuse: Chhabra et al., 2016). Just like the multidimensional RRT, this technique might be too cognitively demanding for respondents, as it combines two consecutive, interdependent questions. Moreover, it is unclear whether the method might really make researchers unaware about the usage of the randomizing device, which is the basic protection mechanism of the whole method.

The cheater detection model (Clark and Desharnais, 1998) is also based on the unrelated question RRT. In the cheater detection model, there are two sub-samples with the neutral question as the "gatekeeper" (Fig. 9). This allows for the estimation of respondents who answered "no" to both questions. Although this can detect this "superficial" cheating, it's not possible to detect those who answer yes for the neutral question and then "no", even if they have in fact performed the sensitive behavior. Nonetheless, it provides a good baseline for the level of cheating occurring.

The $R R T /$ crosswise design adopts the unrelated question with known prevalence to signal noncompliance. For example, if the unrelated

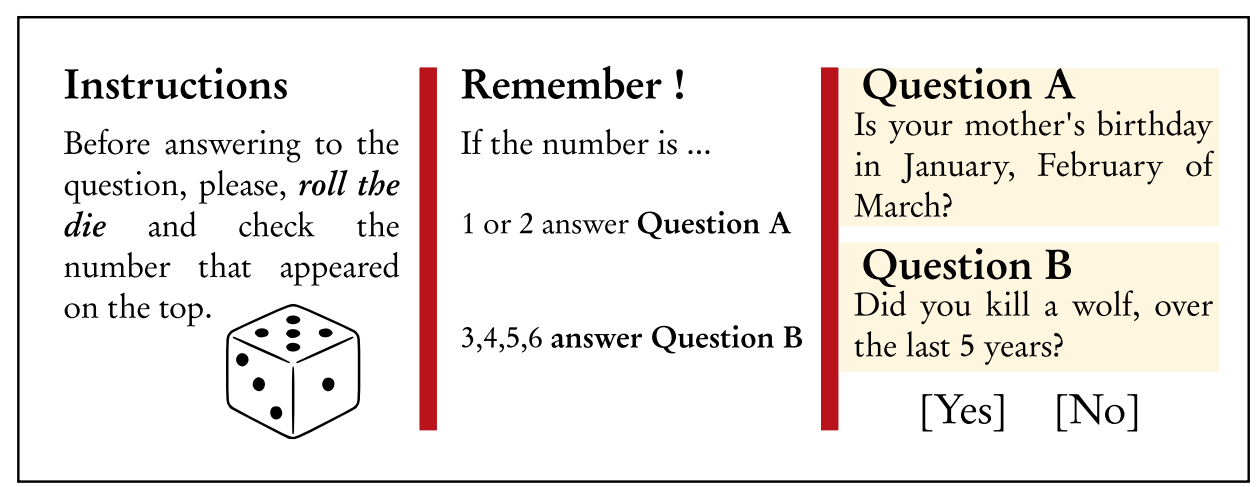

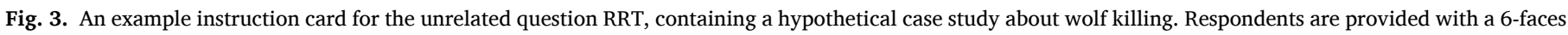

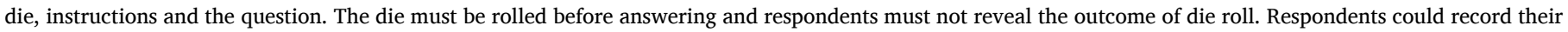
answers on a self-administered questionnaire (like in this example), or answer to an enumerator. 


\section{Instructions}

Before answering to the question, please, roll the die and check the number that appeared on the top.

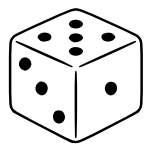

Remember !

If the number is ...

1 or 2 answer Question A

3,4,5,6 answer Question B

\section{Question A}

I have never hunted within a protected area.

\section{Question B}

At least once, I hunted

within a protected area.

Fig. 4. An example instruction card for the mirrored question RRT, containing a hypothetical case study about illegal hunting. Respondents are provided with a 6faces die, instructions and the question. The die must be rolled before answering and respondents must not reveal the outcome of die roll. Respondents could record their answers on a self-administered questionnaire (like in this example), or answer to an enumerator.

\section{Instructions}

You have two decks of cards in front of you. Read the question below.

\section{Question}

Have you ever released poisoned baits around your farm?

\section{Remember !}

If you released poisoned baits, pick a card from the deck on your left. If you did not release any poisoned bait, pick a card from the deck on your right.
Could you please tell us the color of the card?

$$
\text { [Red] [Black] }
$$

Put back the card in the same deck and shuffle it. Thanks!

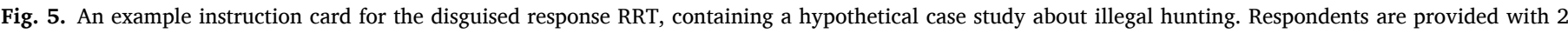

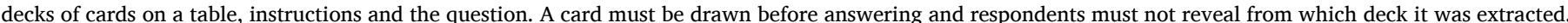
Respondents could record their answers on a self-administered questionnaire (like in this example), or answer to an enumerator.

\section{Instructions}

Please, extract a ball from the urn, without being seen by anyone. Look at the color of the ball and answer the question

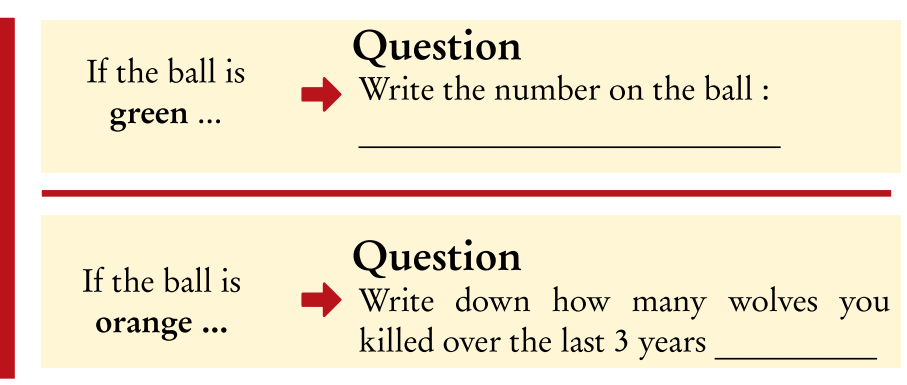

Fig. 6. An example instruction card for the quantitative RRT, containing a hypothetical case study about wolf persecution from herders. Before answering, respondents draw a ball from a sealed vessel. Balls are numbered with numbers from a known Poisson distribution. If the ball is green they are asked to write or state the number on the ball, while if the ball is orange they can write or state down how many wolves they killed. Respondents can also simply report a number to an interviewer. Privacy is protected if the color of the ball is seen by respondents only. (For interpretation of the references to color in this figure legend, the reader is referred to the web version of this article.) question is "Is your age an even number?", it is possible to check if the answers to this question align with the age stated within the survey. This can improve the estimation of sensitive attributes through a weighted conditional likelihood estimator (Tu and Hsieh, 2017). This technique has not been applied in a conservation setting.

Item response theory (IRT) has been proposed to estimate the prevalence of a sensitive behavior based on multiple RRT questions, while indicating the degree of noncompliance. Chang et al. (2018) applied IRT to understand the prevalence of illegal bird hunting by using three distinct RRT questions about three types of bird, e.g. "Have you ever hunted partridge?", "Have you ever hunted bulbuls?", etc. By summing the scores from these single RRTs, they were able to obtain an overall estimate of illegal bird hunting in their sample. In addition, as noncompliance might be signaled from common method bias (i.e. when they answered "no" to all three questions), the use of multiple RRT questions can indicate when a respondent is likely to have answered deceitfully. Although this type of control against bias requires additional analytical work for the researcher, this approach offers considerable opportunities for the analysis of RRT data while ensuring prevalence estimation accuracy.

Chuang et al. (2019) also developed internal consistency tests to detect cheating in questionnaires with multiple RRT. For example, in a questionnaire asking respondents to flip a coin before answering each of multiple RRT, the expected frequency of "yes" and "no" answers should be around 0.5 and departures from this frequency signal noncompliance. Performing a consistency test is important for impact evaluation 


\begin{tabular}{|c|c|c|}
\hline \multirow[b]{2}{*}{ Instructions } & \multicolumn{2}{|c|}{ First die roll } \\
\hline & \multirow[b]{2}{*}{$\begin{array}{l}\text { Remember ! } \\
\text { If the number is ... } \\
1 \text { or } 2 \text { = answer "Yes" } \\
11 \text { or } 12 \text { = answer "No" } \\
\text { between } 3 \text { and } 10=\text { answer } \\
\text { honestly }\end{array}$} & Question A \\
\hline $\begin{array}{l}\text { Before answering } \\
\text { Question A, please, roll } \\
\text { the colored die with the } \\
\text { numbered faces and } \\
\text { check the number that } \\
\text { appeared on the top. }\end{array}$ & & $\begin{array}{l}\text { Over the last } 3 \text { years, } \\
\text { did you kill any wolf? }\end{array}$ \\
\hline \multirow{9}{*}{$\begin{array}{l}\text { Instructions } \\
\text { Before answering } \\
\text { Question B, please, roll } \\
\text { the colored die again } \\
\text { and check the number } \\
\text { that appeared on the } \\
\text { top. }\end{array}$} & \multicolumn{2}{|c|}{ Second die roll } \\
\hline & \multirow{8}{*}{$\begin{array}{l}\text { Remember ! } \\
\text { If the number is ... } \\
\text { between } 7 \text { and } 12 \text { check the } \\
\text { option that applies to you } \\
\text { between } 1 \text { and } 6 \text { roll the die } \\
\text { with the letters on its faces. } \\
\text { Check the option with the } \\
\text { letter that appeared. }\end{array}$} & Question B \\
\hline & & $\begin{array}{l}\text { Over the last } 3 \text { years, how } \\
\text { many wolves did you kill? }\end{array}$ \\
\hline & & A - I did not kill any wolf \\
\hline & & B - Just 1 wolf \\
\hline & & C - Between 2 and 3 wolves \\
\hline & & D - Between 4 and 5 wolves \\
\hline & & E - Between 6 and 10 wolves \\
\hline & & F - More than 10 wolves \\
\hline
\end{tabular}

Fig. 7. An example instruction card for the multidimensional RRT, containing a hypothetical case study about wolf persecution from herders. Respondents are provided with a 12-faced colored die, with numbers on it, and with a 6-faces die with letters from A to F on its faces. They are asked to roll the die colored die first, answer to Question A, and then move to question B. The technique is mostly suitable for self-administered questionnaires.

\begin{tabular}{|c|c|c|}
\hline \multirow{3}{*}{$\begin{array}{l}\text { Instructions } \\
\text { In front of you } \\
\text { there is a deck of } \\
\text { cards. Draw a } \\
\text { card, look at its } \\
\text { symbol and } \\
\text { answer the } \\
\text { question on the } \\
\text { same row. }\end{array}$} & First set of questions & \\
\hline & $\begin{array}{ll}\text { The card is a heart } & \text { Question A } \\
\text { or a diamond }\end{array} \Rightarrow \begin{array}{l}\text { Is Question C too sensitive to be answered } \\
\text { face-to-face? In case it is not sensitive, } \\
\text { check it directly. }\end{array}$ & $\begin{array}{l}{[\mathrm{Yes}]} \\
{[\mathrm{No}]}\end{array}$ \\
\hline & $\begin{array}{ll}\text { The card is a } \\
\text { club or a spade }\end{array} \quad \begin{array}{l}\text { Question B } \\
\text { Is your mother born in January, } \\
\text { February, or March ? }\end{array}$ & $\begin{array}{l}{[\mathrm{Yes}]} \\
{[\mathrm{No}]}\end{array}$ \\
\hline \multirow{3}{*}{$\begin{array}{l}\text { Instructions } \\
\text { Draw another } \\
\text { card, look at its } \\
\text { symbol and } \\
\text { answer the } \\
\text { question on the } \\
\text { same row. }\end{array}$} & Second set of questions & \\
\hline & $\begin{array}{ll}\text { The card is a heart } & \text { Question C } \\
\text { or a diamond } & \text { Over the last } 3 \text { years, did you } \\
\text { kill one, or more, wolves? }\end{array}$ & $\begin{array}{l}{[\mathrm{Yes}]} \\
{[\mathrm{No}]}\end{array}$ \\
\hline & $\begin{array}{ll}\text { The card is a } & \text { Question D } \\
\text { club or a spade } & \text { Is your mother born in January, } \\
& \text { February, or March ? }\end{array}$ & $\begin{array}{l}{[\mathrm{Yes}]} \\
{[\mathrm{No}]}\end{array}$ \\
\hline
\end{tabular}

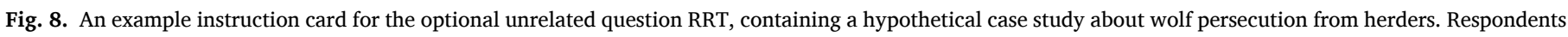

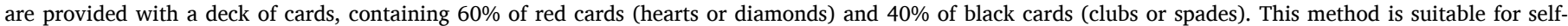
administered questionnaires only. (For interpretation of the references to color in this figure legend, the reader is referred to the web version of this article.)

purposes, which SQTs are increasingly being used for; for example, noncompliance may actually be less prior to a campaign intended to reduce the sensitive behavior, and more after the campaign, due to norm pressure, thus obscuring accurate estimations of change (Camilotti,
2016). Although tests for internal consistency cannot directly measure such attributes, they can provide some indication of the trust researchers can have in their RRT estimations. 


\section{Instructions}

Before answering to the question, think about your best friend and his/her birthday.

\section{Remember !}

If your best friend was born between April and December, answer the question truthfully. If he/she was born in January, February or March, answer "Yes" to the question.

\section{Question}

Over the last 3 years, did you kill one, or more, wolves?

\section{[Yes] $[\mathrm{No}]$}

Fig. 9. An example instruction card for the cheater detection model, containing a hypothetical case study about wolf persecution from herders. Respondents could complete a self-administered form or answer to an interviewer.

\subsection{The unmatched count technique (list experiments) and the item sum technique}

The Unmatched Count Technique (hereafter UCT, also known as "list experiment”) protects respondents' privacy by asking them simply to indicate how many behaviors apply to them, from a list of non-sensitive and sensitive behaviors. They are generally perceived as simpler than RRT, due to not having a randomizing device, and therefore appear to be more attractive to researchers with limited time and money. However, there are some significant limitations with UCT, which we will discuss at greater length below. Within this section, we will also describe preexisting versions of UCT and advances that have been proposed since 2015.

\subsubsection{Pre-existing UCTs}

In its classical version, the item count technique (Raghavarao and Federer, 1979) respondents are separated into two groups, one designated as the control group and one as the treatment. Each group is shown a set of behaviors and asked how many of these they have done. The control group is only shown innocuous behaviors, while the treatment group is shown the same set of innocuous behaviors plus the sensitive behavior of interest (Fig. 10). The difference between the control and the treatment groups represents the mean prevalence of the target sensitive behavior in the population. The item count technique is argued to reduce sensitivity by having respondents only give a numeric response; thus, the researcher never knows if one of the behaviors performed by the respondent was the sensitive one of interest. Although this method requires significant checking and piloting of the behaviors utilized (Hinsley et al., 2019), it is also simple to check for internal consistency (Blair and Imai, 2012). For example, researchers should ensure that there are no "floor effects", where individuals would have to state
" 0 ". Therefore, if the researcher finds multiple " $0 \mathrm{~s}$ " within their sample, they can determine that respondents were probably actively lying (e.g. Hinsley et al., 2017). Nonetheless, a major advantage of the UCT lies in the trust it inspires in respondents: Hoffmann et al. (2017) found that the UCT was perceived as more capable of protecting respondents' privacy then the crosswise method, the stochastic lie detector and the cheating detection model. Therefore, this method was considered to be particularly suitable for eliciting behavior prevalence estimations of extremely sensitive behaviors.

In double list UCT, the respondents are further separated, with two sets of non-sensitive behaviors, $A$ and $B$, and the appended sensitive item switched off between the lists (Glynn, 2013. Fig. 11). This method can in principle narrow the large statistical errors that characterize UCT (e.g. Davis et al., 2019, 2020a, 2020b). However, to our knowledge it has not been applied in a conservation setting. In addition, where the perceived sensitivity of certain behaviors is unknown, the design of the double list UCT can provide some measure about this point.

In their study of women's sexual behaviors in Côte d'Ivoire, Chuang et al. (2019) crafted multiple lists of 48 statements total, divided into two sets. In their "treatment" set, the lists included innocuous as well as semi-sensitive statements, e.g. "Many women have an abortion even though it is illegal". They could therefore compare statements between their control set to see whether women generally answered at a lower prevalence for any perceived sensitive statements. However, this consistency and sensitivity check comes with risk to the respondents. Ceiling effects occur when a respondent states that they have done and/or agree with all the statements presented, thus negating their ability to give an anonymous response. Chuang et al. (2019) found that ceiling effects occurred as affirmative responses grouped, e.g. women who were known to have had an abortion (i.e. by stating that they had done all four behaviors given in a UCT list) were also more likely to agree with all four

\begin{tabular}{|c|c|c|}
\hline Instructions & Control & Treatment \\
\hline \multirow{5}{*}{$\begin{array}{l}\text { Please, read the list and } \\
\text { tell us how many } \\
\text { behaviors applied to you } \\
\text { during your stay at the } \\
\text { Park. You don't need to } \\
\text { tell us which behaviors, } \\
\text { just their total number. }\end{array}$} & Looking for mushrooms & Looking for mushrooms \\
\hline & Picking up berries & Picking up berries \\
\hline & Going fishing & Going fishing \\
\hline & Taking pictures & Taking pictures \\
\hline & & Collecting petrified wood \\
\hline
\end{tabular}

Fig. 10. An example instruction card for the classic 2-groups item count technique, containing a hypothetical case study about illegal petrified wood removal from a protected area (Cialdini et al., 2006). Respondents are randomly allocated to the Control or Treatment condition and should write on the questionnaire, or tell the interviewer the number of actions they did, during their stay at the Park. The sensitive behavior is highlighted. 


\begin{tabular}{|c|c|c|}
\hline \multirow{7}{*}{$\begin{array}{l}\text { Instructions } \\
\text { Please, read the list and } \\
\text { tell us how many } \\
\text { behaviors applied to you } \\
\text { during your stay at the } \\
\text { Park. You don't need to } \\
\text { tell us which behaviors, } \\
\text { just their total number. }\end{array}$} & \multicolumn{2}{|c|}{ First wave } \\
\hline & Control (A) & Treatment (A) \\
\hline & Looking for mushrooms & Looking for mushrooms \\
\hline & Picking up berries & Picking up berries \\
\hline & Going fishing & Going fishing \\
\hline & Taking pictures & Taking pictures \\
\hline & & Collecting petrified wood \\
\hline & Seco & wave \\
\hline Administration & Control (B) & Treatment (B) \\
\hline Respondents & Camping & Camping \\
\hline $\begin{array}{cc}\checkmark & \searrow \\
\text { Control (A) } & \text { Treatment (A) }\end{array}$ & Mountain biking & Mountain biking \\
\hline & Hiking trails & Hiking trails \\
\hline Treatment (B) Control (B) & Climbing & Climbing \\
\hline & & Collecting petrified wood \\
\hline
\end{tabular}

Fig. 11. An example instruction card for the double list unmatched count technique, containing a hypothetical case study about illegal petrified wood removal from a protected area (Cialdini et al., 2006). Respondents are randomly allocated to the Control or Treatment condition in the first wave, and should write on the questionnaire, or tell the interviewer the number of actions they did, during their stay at the Park. Then on the second wave, they are allocated to the opposite condition. Control lists in the first and second wave contain two different sets of behaviors. The sensitive behavior is highlighted. sensitive statements, such as "Many women have an abortion even though it is illegal".

In single sample count UCT, the sample is not split into two groups. Instead, the entire sample is asked about the sensitive behavior, as well as being asked four non-sensitive questions where each of the questions must have a 50\% yes rate (Petróczi et al., 2011; Fig. 12). Thus, the estimated prevalence of the behavior concerned will be any deviation from $50 \%$. Although this method was conceived to overcome the large standard errors of UCT, the method still suffered from this issue. Similarly to double list UCT, there have been no attempts in the conservation literature to apply this method.

The item sum technique (IST) is an extension of the UCT where respondents are asked to give summed quantitative answers (Fig. 13). Trappman et al. (2017) originally proposed IST using the example of undeclared work in Germany (i.e. low-level tax fraud). They found it was useful for more accurately estimating the number of undeclared hours of work by respondents, and like UCT, was not "cognitively demanding" compared to RRT and its variations. Although it is only sensible to use it for scenarios where the researcher wants to make quantitative estimates, e.g. number of wolves killed a year (Fig. 9), it seems to be a robust method in terms of overcoming biases, albeit afflicted with the very large standard errors that also characterize UCT.

\subsubsection{Advances in UCTs}

In the longitudinal unmatched count technique (Gaia and Al Baghal, 2019) the same sample of respondents is given the control list and the sensitive list at different points in time. This method reduces the statistical error that UCT suffers from; however, the method requires a significant time investment, and as with UCT, if the non-sensitive items are not carefully chosen the method can still generate incorrect estimates. To date, the method has never been applied for conservation issues.

In the negative binomial and Poisson UCT (Tian et al., 2017), respondents are divided into a control and a treatment group. Rather than asking respondents how many separate behaviors they have engaged in, respondents in the control group are asked to answer a non-sensitive count question, while those in the treatment condition sum this answer with 1 , if they have engaged in a target sensitive behavior

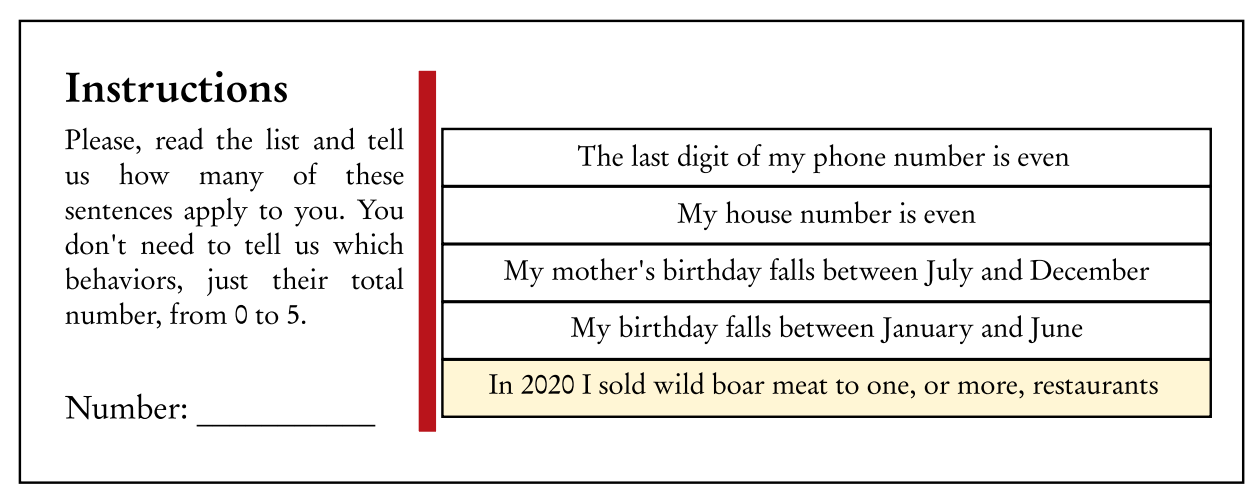

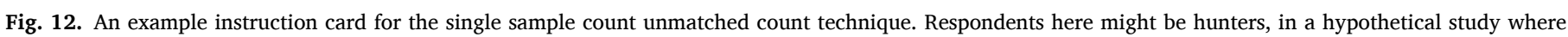

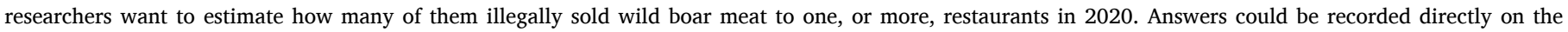
questionnaire (like here), or can be dictated to an interviewer. The sensitive behavior is highlighted. 


\begin{tabular}{|c|c|c|}
\hline \multirow{6}{*}{$\begin{array}{l}\text { Instructions } \\
\text { Please, read the list and tell } \\
\text { us how many individuals, of } \\
\text { the species in the list, you } \\
\text { killed over the last } 12 \\
\text { months. You don't need to } \\
\text { tell us how many individuals } \\
\text { of each species, just the total } \\
\text { number of animals killed. }\end{array}$} & Control & Treatment \\
\hline & Roe deer & Roe deer \\
\hline & Red deer & Red deer \\
\hline & European mouflon & European mouflon \\
\hline & Alpine chamois & Alpine chamois \\
\hline & & Gray wolf \\
\hline
\end{tabular}

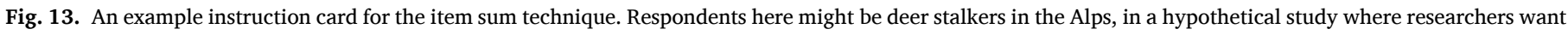

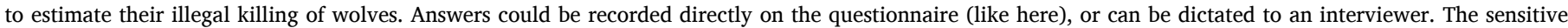
behavior is highlighted.

(Fig. 14). The respondent then states the sum, which anonymizes individual answers. While this method, altogether with Poisson and Negative Binomial models, can in principle overcome floor and ceiling effects, it introduces large variability in the data, which might jeopardize the accurate estimation of behavioral prevalence.

The Poisson-Poisson UCT is an extension of the Poisson UCT, which aims to understand what covariates could affect the responses to the sensitive question of interest (Liu et al., 2019). Respondents are divided into two groups, with Group 1 asked to choose a random number from a Poisson distribution and report it. Group 2 is also asked to choose a random number from the Poisson distribution, but to sum this number with 1 , if they have engaged in the sensitive behavior of interest (Fig. 15). Through this method, one can also collect covariate data such as age and gender. However, it is important to emphasize that background information about respondents is still collected with conventional direct answers. It is therefore important that questionnaires are self-completed and that the target population is large enough to prevent anyone from back-tracing respondents. Researchers can then explore the effect of these variables on response using a standard Poisson linear regression; however, the method is still characterized by highly variable estimates.

In the double list item sum technique (Krumpal et al., 2018), the logic exactly follows the double list UCT. However, the DLIST can easily be extended to include additional sensitive questions (e.g. Perri et al., 2018). The DLIST greatly reduces the variability intrinsic in standard IST, but it might be cognitively demanding, and requires further testing.

\subsection{Non-randomized techniques}

Non-randomized techniques ask respondents to provide a conjoint answer to two or more questions, including the sensitive question of interest. They do not require a randomizing device, and therefore their field administration is made easier than RRT. Moreover, some of them, like the crosswise model, make it challenging for respondents to give deceitful answers.

\subsubsection{Pre-existing non-randomized techniques}

In the crosswise model, respondents are asked only to tell whether they provided the same answer, or two different answers, to a couple of statements. One statement is the non-sensitive question, whose prevalence in the target population must be known in advance and the second statement is about the sensitive behavior of interest (Fig. 16).

Compared to direct questioning, the UCT, the stochastic lie detector and the cheating detection model, Hoffmann et al. (2017) found that the crosswise model was easier to understand for respondents, and that the method was deemed to be good at protecting individual privacy, being outperformed only by the UCT. Furthermore, Meisters et al. (2020) found that providing respondents with detailed instructions and additional comprehension checks might improve its accuracy. The performances of the crosswise model are still debated: while some authors found that the technique is sensitive to false positives (Höglinger and Diekmann, 2017), validation studies based on experimentally induced cheating behavior (Hoffmann et al., 2015) and known prevalence of sensitive behaviors (Korndörfer et al., 2014) supported its positives as a specialized questioning technique.

The triangular model (Yu et al., 2008) is similar to the crosswise model, in the sense that respondents are provided with a couple of questions: a safe question, with known prevalence (e.g. What month were you born in?); and a sensitive question, about the sensitive trait which should be estimated. However, rather than indicating whether they provided the same answer or not, respondents are asked whether they answered "no" to both questions, or whether they affirmed one

\begin{tabular}{|c|c|c|}
\hline Instructions & Control & Treatment \\
\hline $\begin{array}{l}\text { Read the following } \\
\text { questions and aswer. }\end{array}$ & $\begin{array}{l}\text { How often have you } \\
\text { visited Hanoi, over the } \\
\text { last } 12 \text { months? } \\
\text { Report the number of } \\
\text { times. } \\
\text { N.visits: }\end{array}$ & $\begin{array}{l}\text { How often have you visited } \\
\text { Hanoi, over the last } 12 \\
\text { months? Add } 1 \text { to the } \\
\text { number of visits to Hanoi, if } \\
\text { you also used tiger bone } \\
\text { glue, over the last } 12 \text { months }\end{array}$ \\
\hline
\end{tabular}

Fig. 14. An example instruction card for the negative binomial/Poisson count UCT, containing a hypothetical case study about tiger bone glue usage in Vietnam. Respondents are allocated at random to control or treatment groups. 


\begin{tabular}{|c|c|c|}
\hline Instructions & Control & Treatment \\
\hline $\begin{array}{l}\text { Choose one of the } \\
\text { following numbers. }\end{array}$ & \multirow[t]{7}{*}{$\begin{array}{l}\text { Report the number you } \\
\text { chose: }\end{array}$} & \multirow{7}{*}{$\begin{array}{l}\text { If you used tiger bone } \\
\text { glue, over the last } 12 \\
\text { months, add } 1 \text { to the } \\
\text { numer you chose. If you } \\
\text { do not use tiger bone } \\
\text { glue, report the number. } \\
\text { Number: }\end{array}$} \\
\hline 68447423651522425103 & & \\
\hline 53333445354852367136 & & \\
\hline 51574578342712475465 & & \\
\hline $\begin{array}{l}2454447458666384658 \\
101113787814571066448\end{array}$ & & \\
\hline 25738546210936761073 & & \\
\hline 4864566345689144587 & & \\
\hline
\end{tabular}

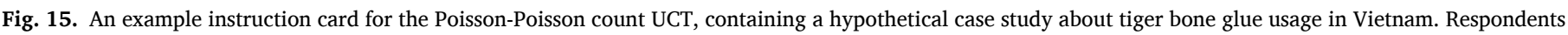
are allocated at random to control or treatment groups. Numbers on the list are extracted from a Poisson distribution with mean and variance equal to 5 .

\begin{tabular}{|c|c|c|}
\hline $\begin{array}{l}\text { Instructions } \\
\text { Please, read Statement A } \\
\text { and Statement B. Then, } \\
\text { answer the question. }\end{array}$ & $\begin{array}{l}\text { Statement A } \\
\text { My mother was born } \\
\text { between August and } \\
\text { December. } \\
\text { Statement B } \\
\text { I consumed pangolin } \\
\text { meat, at least once. }\end{array}$ & $\begin{array}{l}\text { Question } \\
\text { Are both Statement A } \\
\text { and Statement B, true or } \\
\text { false (you would have } \\
\text { answered True/True and } \\
\text { False/False to them)? } \\
\qquad \text { [Yes] [No] }\end{array}$ \\
\hline
\end{tabular}

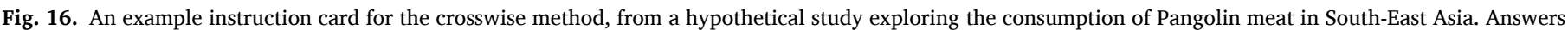

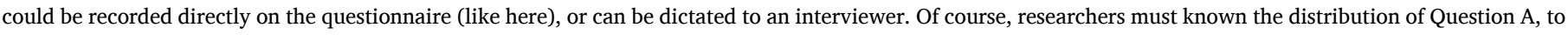
estimate question $\mathrm{B}$.

(Fig. 17). It is easy to see that the triangular model provides respondents with a clear self-protective strategy, as they could simply state that they answered "no" to both questions. Hoffmann et al. (2020) found that, overall, the crosswise model was preferred, as it is harder for respondents to violate instructions. In facts, the crosswise model asks respondents only if they gave the same or two different answers to the two questions, without referring to any particular response option, like "yes" or "no". Therefore respondents cannot just simply declare to have answered "no" to both questions, a strategy that they can endorse whenever they do not trust the triangular model and want to deny any illegal behavior, and tend to comply with instructions from the crosswise model.

\subsubsection{Advances in non-randomized techniques}

In the extended crosswise model (Heck et al., 2018), respondents are randomly assigned to two groups, as opposed to the crosswise model, where the sample is not split into multiple groups. The groups receive the same sensitive question, but two different, non-sensitive questions, with a known, and complementary prevalence in the target population (Fig. 18). If respondents in group A receive the question "Is your mother's birthday between June and December?", respondents in group B should receive the question "Is your mother's birthday between January and May?". As with the crosswise model, the respondent then states whether their answer is the same to both the non-sensitive and sensitive question, or whether the responses are different. The extended

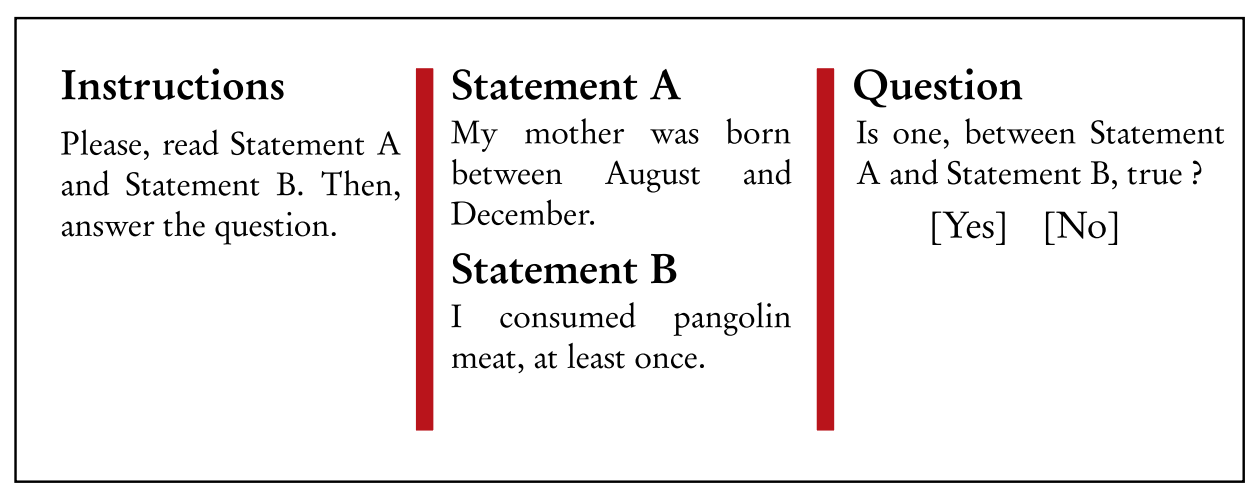

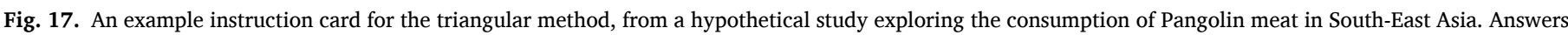

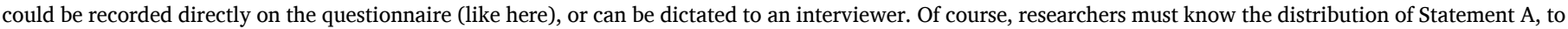
estimate the frequency of Statement B. 


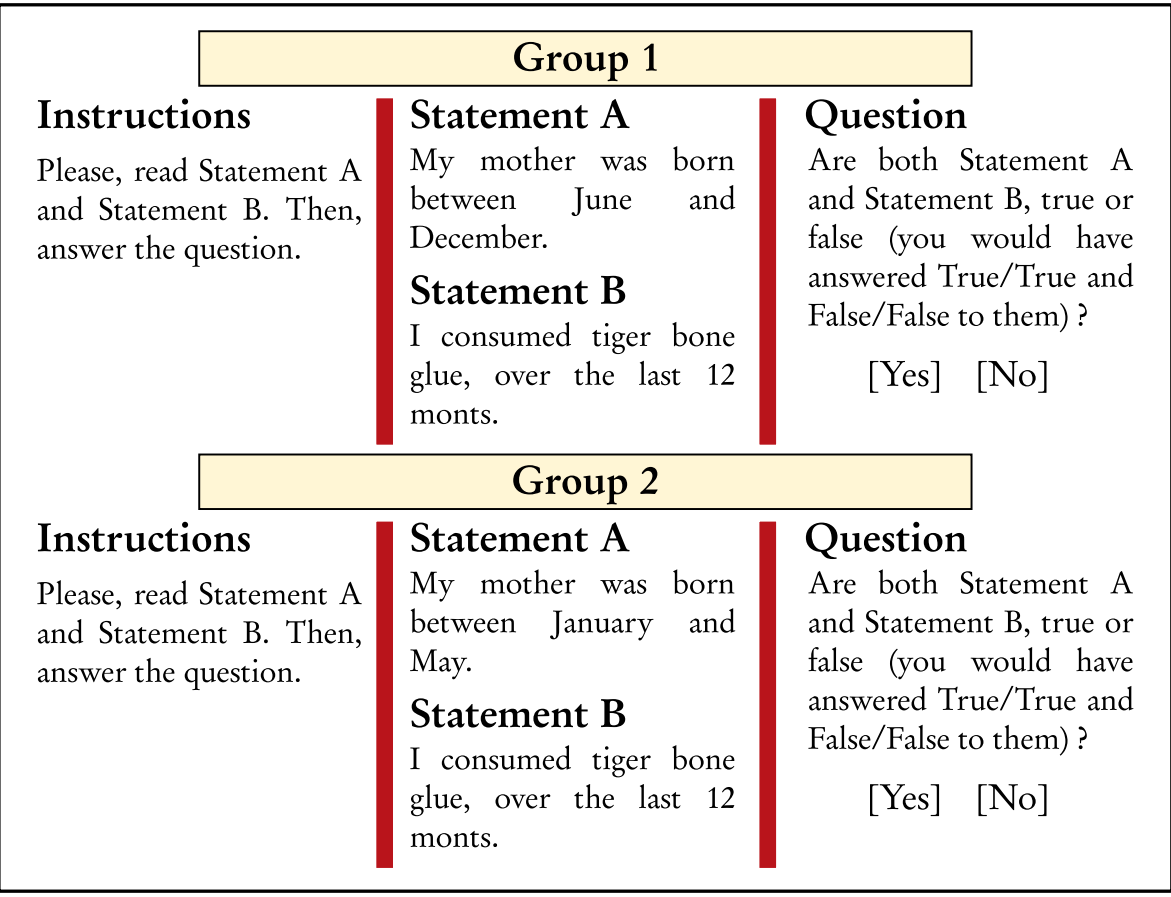

Fig. 18. An example instruction card for the extended crosswise method, with a hypothetical case study about tiger bone glue consumption in Vietnam. Respondents are allocated at random to Group 1 or Group 2. The temporal distribution of births, and therefore the frequency of Statement A is known. Respondents could complete a self-administered questionnaire or answer to an interviewer.

crosswise model, while guaranteeing the same statistical efficiency of the crosswise model, can also enable researchers to detect respondent's noncompliance with instructions.

The dual non-randomized response technique and the alternating nonrandomized response technique have been proposed to actively account for deception in the triangular model (Wu and Tang, 2016). In the dual non-randomized response technique, the sample is split into two groups, with two different non-sensitive questions. The method proceeds exactly as it would normally, but by incorporating the split groups and different sensitive questions, noncompliance can be measured (Fig. 19).

In the alternating non-randomized response technique, the sample is also split into two groups, but only one non-sensitive question is used

\begin{tabular}{|c|c|c|}
\hline \multicolumn{3}{|c|}{ Group 1} \\
\hline Instructions & Statement A & Question \\
\hline $\begin{array}{l}\text { Please, read Statement A } \\
\text { and Statement B. Then, } \\
\text { answer the question. }\end{array}$ & $\begin{array}{l}\text { The last digit of my } \\
\text { mobile phone number is } \\
\text { even. } \\
\text { Statement B } \\
\text { I consumed tiger bone } \\
\text { glue, over the last } 12 \\
\text { monts. }\end{array}$ & $\begin{array}{l}\text { Is at least one statement, } \\
\text { between Statement A } \\
\text { and Statement B true? }\end{array}$ \\
\hline & Group 2 & \\
\hline Instructions & Statement A & Question \\
\hline $\begin{array}{l}\text { Please, read Statement A } \\
\text { and Statement B. Then, } \\
\text { answer the question. }\end{array}$ & $\begin{array}{l}\text { My mother was born } \\
\text { between January and } \\
\text { September. } \\
\text { Statement B } \\
\text { I consumed tiger bone } \\
\text { glue, over the last } 12 \\
\text { monts. }\end{array}$ & $\begin{array}{l}\text { Is at least one statement, } \\
\text { between Statement A } \\
\text { and Statement B true? }\end{array}$ \\
\hline
\end{tabular}

Fig. 19. An example instruction card for the dual non randomized response technique, with a hypothetical case study about tiger bone glue consumption in Vietnam. Respondents are allocated at random to Group 1 or Group 2. The frequency of Statement A is known, but Statement A in the two groups should have a different probability. Respondents could complete a self-administered questionnaire or answer to an interviewer. 
(Fig. 20). A key difference from the dual non-randomized response technique is that the triangle is "flipped" in one of the groups, in that the respondent marks outside of the triangle if they do not have the sensitive characteristic, but would say yes to the non-sensitive question. Both the two methods have been argued to provide more accurate estimates than the triangular model, with the potential to more accurately capture the "true" prevalence of the behavior in question. However, they still suffer from high variability in prevalence estimation, even for high sample sizes (e.g. $\mathrm{n} \sim 1000$; Wu and Tang, 2016).

\subsection{Other SQTs not considered in previous reviews}

There are two techniques that were not considered in Nuno and St John (2015), despite having been invented before 2015, and which we note could be adopted to measure sensitive questions in conservation. Neither of these methods appears to have had any significant theoretical advancement since their proposal.

Endorsement experiments measure sensitive attitudes. In endorsement experiments, participants are randomly assigned to a treatment and a control group, both expressing their support for a policy on a traditional 5- or 7- points bipolar scale (Blair et al., 2014; Rosenfeld et al., 2016). However, the treatment groups specifically recall a certain issue, which could influence the evaluation of the baseline scenario (Fig. 21).

The difference in scores between these two groups reveals the importance the specific issue at hand. In endorsement experiments individuals never need to explicitly give their opinions on a sensitive topic, like in direct answers, e.g. whether they think rhino horn consumption should be legalized, but rather they just evaluate a certain political actor, conditionally on its behavior about a certain issue. In principle, respondents could say that their negative evaluation depended upon their prejudices against the policy actor itself, not its behavior about a specific issue. It is worth noting that this privacy protection mechanism characterizes some conjoint surveys, like factorial survey experiments. However, it must be acknowledged that such of a level of privacy protection is somewhat weaker than that guaranteed by RRTs or UCTs, because individual answers are not masked by the addiction of noise provided by a randomizing device or by grouping multiple answers. In addition, endorsement experiments are even more statistically inefficient than UCT, which is already characterized by overly high variability (e.g. Davis et al., 2020a, 2020b), and as such large samples are often needed (Rosenfeld et al., 2016). Nonetheless, the technique is quite easy to design and administer, and thus may be attractive to conservationists with limited resources.

In the ballot box method (Gregson et al., 2002) respondents are provided with voting tokens, with a color and a number corresponding to the various questions. An enumerator then explains the technique and reads the questions. Respondents put their tokens into a sealed box, which is opened at the end of the study.

The ballot box method is similar, in terms of privacy-protecting mechanism to the bean method (Lau et al., 2011): respondents provide their anonymous answers and their privacy is protected by the sealed vessel, which is opened at the end of the study (in the case of comparable bean method, the vessel is opened at the end of every day, see Jones et al., 2020). This mechanism is highly effective for measuring sensitive behaviors at public events, where multiple answers are collected at the same time, blurring individual answers (e.g. during meetings with stakeholders). The ballot box could be extremely easy to implement and understand. Bova et al. (2018), adopted the BB in faceto-face surveys structured interviews with recreational anglers in South Africa, finding that the technique provided higher estimates of non-compliant behaviors, than the RRT and direct questioning.

\subsection{New SQTs identified in literature search}

We identified four new SQT methods that had not been covered in 2015: the parallel model, the pair method, the list method, and the person count technique. None of these techniques have had any significant advance.

The parallel model (Tian, 2014), is a non-randomized technique combining two non-sensitive questions, with known prevalence, with a sensitive question of interest. The parallel model is based on two questions (Fig. 22).

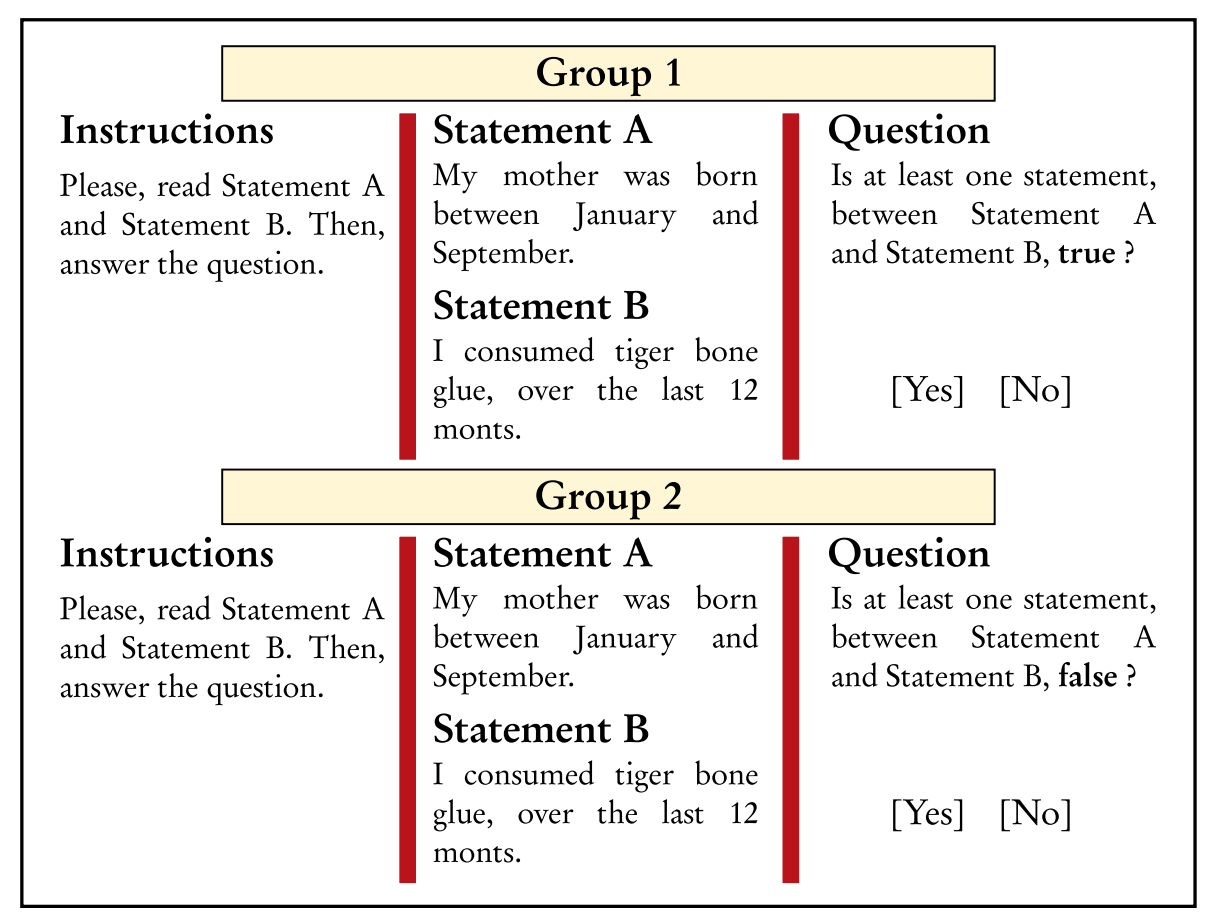

Fig. 20. An example instruction card for the alternating non-randomized response technique, with a hypothetical case study about tiger bone glue consumption in Vietnam. Respondents are allocated at random to Group1 or Group 2. The frequency of Statement A is known. Respondents could complete a self-administered questionnaire or answer to an interviewer. 


\section{Instructions}

We would like to get your overall opinion of some local authorities. As we read their names, please say if you have a very positive, somewhat positive, neutral, somewhat negative or extremely negative opinion about them.

\section{Control}

The Vietnamese ministry for the Environment.

Very positive opinion Somewhat positive opinion Neutral opinion Somehwat negative opinion Extremely negative opinion

\section{Treatment}

The Vietnamese ministry for

the Environment, who

introduced a law penalizing

rhino horn consumption.

Very positive opinion

Somewhat positive opinion

Neutral opinion

Somehwat negative opinion

Extremely negative opinion

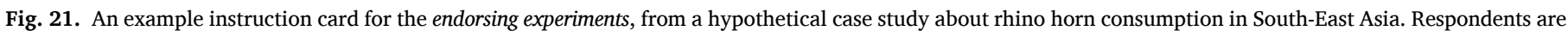
allocated at random to Group 1 or Group 2.

In this case, both the distribution of births through the year, and the distribution of cell phone digits, are known and provide information to estimate the prevalence of chimpanzee meat consumption. Tian (2014) claims the parallel model to be statistically more efficient, and more privacy protecting, than the crosswise model and the triangular model. However, to date, the technique has only once been applied in field conditions (e.g. sexual habits, Tian et al., 2019) and there have been no applications of it in conservation.

The pair method and the list method (Lagerås and Lindholm, 2020) apply to multiple choices. In the pair method the respondent is asked to report his/her chosen option and another option, chosen at random, and to write down the two answers in random order (Fig. 23). In the list method the respondent is presented with a list of options and to indicate whether his/her option is on the list. Different respondents that are shown different lists (Fig. 24). It is easier than the pair method, as it does not require any randomization by the respondent, and privacy protection is even higher. The two methods have never been applied in conservation. The list method is similar to UCT in its random allocation of sets of answers to two groups of respondents. Therefore, like UCT, it might need large sample sizes $(n>1000-2000)$ to reduce variance (Hinsley et al., 2019). The two methods seem suitable to measure preferences when many options are available, as this is their cornerstone of privacy protection, and therefore unsuitable for researchers investigating behaviors with few categories.

In the person count technique (Wolter, 2019), respondents are randomly assigned to a control and a treatment group. In the control group, respondents are asked to think of three people that they know, and state how many of those three would agree with a sensitive statement (e.g. "I use pangolin scales for my health"). In the treatment group, respondents are asked to think of the same three people from their social group, but should also consider themselves and their own preferences when stating the number of people who agree with the sensitive statement. The person count technique overcomes an issue of the nominative technique which is that estimations of how many individuals in a social group perform a sensitive act is challenging to identify, can be inflated and/or vague, and don't concretely capture the actual preferences of the individual being interviewed (e.g. Davis et al., 2019). However, the person count technique could be highly sensitive to floor and ceiling effects, and due to the separation of the sample into two groups, it could suffer from large standard errors, like UCT (Wolter, 2019).

\section{Discussion}

Worldwide, there is a growing need to quantify and understand noncompliance with natural resource use, to better address and reduce unsustainable resource use (Solomon et al., 2015). As questionnaires are still the dominant approach for this task, SQTs are attractive to conservationists, as they promise to measure human behavior and attitudes in an unbiased way. Our findings indicate that SQTs have blossomed over the last five years, with both the invention of entirely new methods and the development of many new applications of existing techniques. It is encouraging to see that this development has gone beyond RRT, the most common among the SQTs, and involves methods which do not require any randomization device. This in particular is promising for being more easily adopted by conservationists working in the field. Some methods, like the ballot box method and bean method, while not having a sophisticated protection mechanism, do keep responses private and appear to be simple and adaptable to many situations (Bova et al., 2018; Jones et al., 2020).

SQTs still pose some major challenges to researchers. First, while they can eliminate the risk of privacy disclosure and sanctions, they do not entirely resolve respondents' concerns about the misinterpretation of their answers, or when answering about taboos (e.g. St. John et al.,

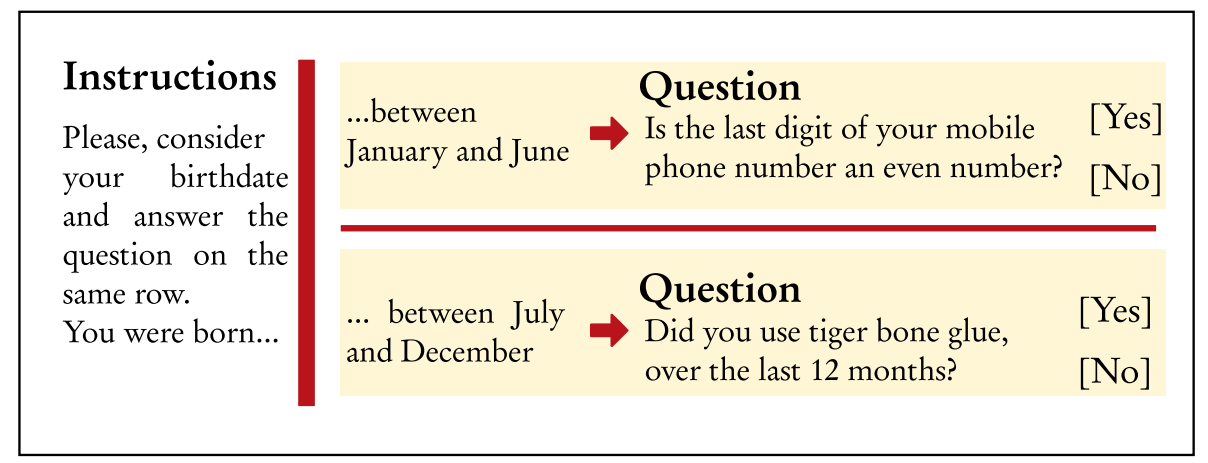

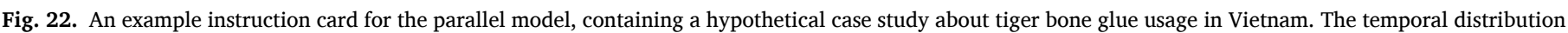

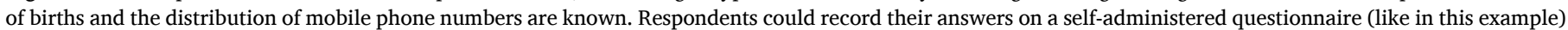
or answer to an interviewer. 


\begin{tabular}{|c|c|c|}
\hline Instructions & Gambian pouched rat & \multirow{8}{*}{$\begin{array}{l}\text { Question } \\
\text { Write down the two } \\
\text { species in any order you } \\
\text { want, below here: }\end{array}$} \\
\hline \multirow{7}{*}{$\begin{array}{l}\text { Please, read the list here } \\
\text { on the right. } \\
\text { Choose the species that } \\
\text { is your favourite meat, } \\
\text { and another species, } \\
\text { chosen at random. }\end{array}$} & Red river hog & \\
\hline & Chimpanzee & \\
\hline & $\begin{array}{l}\text { Crocodile } \\
\end{array}$ & \\
\hline & Water chevrotain & \\
\hline & Buffalo & \\
\hline & Porcupine & \\
\hline & Sitatunga & \\
\hline
\end{tabular}

Fig. 23. An example instruction card for the pair method, containing a hypothetical case study about preferences for chimpanzee meat consumption, compared to other bushmeat species (from van Vliet et al., 2015). Respondents could record their answers on a self-administered questionnaire (like in this example) or answer to an interviewer. Alternatively, they can also check the two species on the list, with a cross-mark. To increase privacy protection, lists can be extended to a higher number of species.

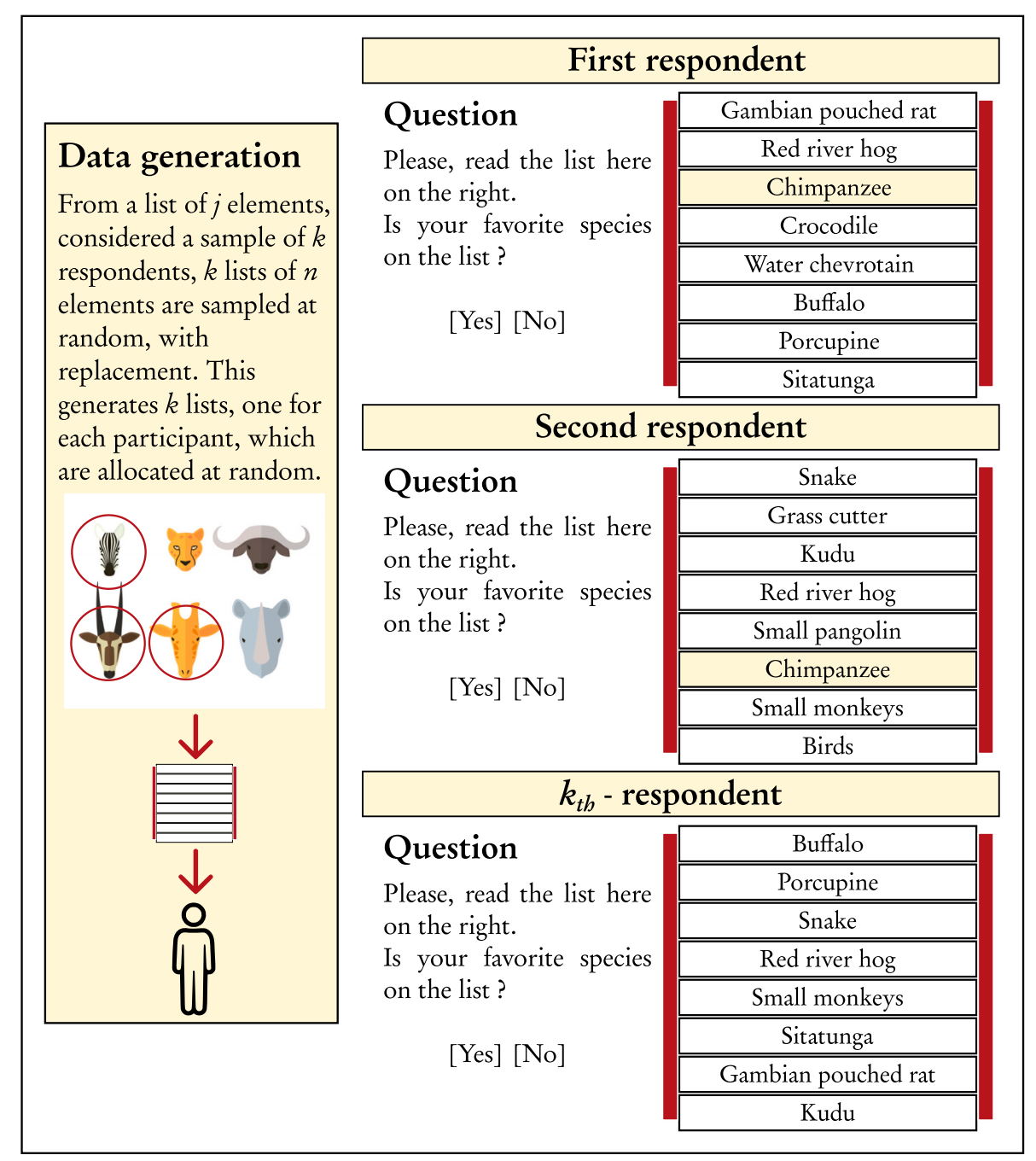

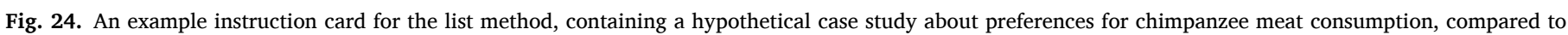

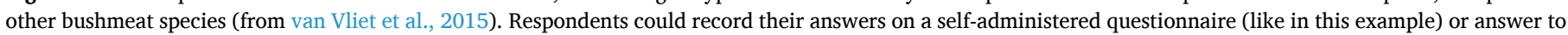
an interviewer. Each respondent has a different list, generated at random. Lists might contain sensitive questions, or not.

2018). Second, due to their cognitive load, and their sometimes complex functioning, SQTs can in some situations not be understood by respondents (e.g. Davis et al., 2019). While some methods, like crosswise model and unmatched count technique (UCT) seem to be trusted and understood (Hoffmann et al., 2017), other studies have suggested that the interpretation of SQTs might be tricky even for highly educated respondents (Jerke et al., 2019). These two aspects certainly call for more laboratory experiments, that can illuminate respondents' psychology to the various SQTs design.

At the same time, we also call for a push, particularly in conservation, of greater experimentation with SQTs in the field. Many of the new methods and advances identified in this study have received relatively little or no practical application. Even techniques that are considered statistically valid, may not in fact be scientifically valid, if they are created based on erroneous assumptions about how humans act or think (Navarro, 2019). For example, a statistical model may show that an SQT 
is robust if it is tested on pre-existing data where the respondents gave direct answers (e.g. Tian et al., 2007), but in practice the SQT may in fact be too cognitively demanding for respondents and thus it is not scientifically valid in the sense of practical experimentation success.

Testing these methods with field experiments, coupled with qualitative research around the sensitive behavior of interest (Chuang et al., 2019) is ultimately the sole way to diagnose potential problems and to test for their performances. For example, Davis and Glikman (2020) found that the nominative technique was unnecessary in gaining behavior estimates of bear bile use in northern Laos, due to a complete lack of sensitivity around use. Most of the non-randomized techniques reported in Table 1 received little application in the field, and considered their potential for conservation, their testing should be a priority.

A relevant hanging question for many SQTs is sample size. Most techniques require thousands of observations, even more for cheating detection (Clark and Desharnais, 1998; Schröter et al., 2016), and still they can suffer from large estimation errors. Even many recent techniques achieve statistical efficiency only at the price of their practical implementation, through requiring large sample sizes that ultimately become cumbersome (e.g. multinomial RRT, e.g., double list item sum technique, e.g. pair and list method). Especially for conservationists, large samples are often beyond what can be achieved, due to money and time complications in gaining large samples. Moreover, large samples and standard errors could limit the application of SQTs in longitudinal designs. To understand whether small sample sizes could perhaps be effective for some of these techniques, there is a growing need for practical experimentation and subsequently clear guidelines about sample size requirements of the various SQTs. These guidelines would ultimately assist researchers to decide whether, and which, SQTs are feasible for their study.

Moreover, we encourage conservationists to carefully think about why they need SQTs. While many studies aim to quantify the prevalence of sensitive behaviors, many others focus on understanding their drivers. These usually model the influence of covariates over the probability that respondents engage in a certain behavior, but SQTs might not be the best tool for this scope. Many of them do not allow for covariates at all (e.g. bean method, ballot box method) and even those that can generally further worsen their statistical power when doing so. Moreover, while there are implementations of the RRT for randomizing questions to be used as a response variable or as a predictor in a regression model (Cruyff et al., 2016b), there is no way of randomizing both. There are limits to adding noise.

We believe that other methods can be suitable for measuring drivers of sensitive, or deviant, behaviors. For example, respondent-driven sampling (Griffiths et al., 2017) is based on conventional questionnaires, whose data could be easily modeled with no loss of statistical efficiency. Endorsement experiments can be valuable or measuring preferences, and choice experiments (Hinsley et al., 2015) or factorial survey experiments (Auspurg and Hinz, 2014) can be valuable approaches for understanding drivers of individual behavior in conservation. In addition, such techniques can give researchers an understanding of stakeholders' opinions towards broader issues such as regulatory measures or implemented policies, which is data that more "fine scale" SQTs cannot gain, without the fear of repercussions that can characterize direct answers collected from conservation practitioners or employees from environmental agencies.

It is worth noting that although SQTs can preserve individual respondent anonymity, they generally provide aggregate responses at a community level, which can be harmful to communities who are e.g. under heavy oversight by a local government (St. John et al., 2016). In addition, conservationists can themselves influence the implementation of repressive laws through the misapplication of such community-level data (Brittain et al., 2020). It is, therefore, essential for researchers using SQTs to carefully consider the communities they work in, how they can best ensure respondents are protected at every possible level, and how they will use the data they collect in ways that are beneficial to all stakeholders (Brittain et al., 2020). One simple way of overcoming such potential issues is to report data at a higher aggregate level, e.g. province level. However, this decision brings its own challenges and it can limit the quality of information that can be extracted from the data: aggregated data can be less informative for conservation purposes, and hiding the sampling frame can prevent researchers from replicating a certain study, even in the same geographical area. Ultimately, such ethical considerations further emphasize the calls of others that researchers attempting to understand deviant behavior should be given robust training in ethics in research (Brittain et al., 2020; St. John et al., 2016).

\section{Conclusions}

There are a wealth of SQTs that conservationists can use to monitor and understand sensitive topics. Although there are challenges intrinsic in many, if not most, of the methods described here, some may be more applicable to researchers than classic forms of UCT and RRT (e.g. Davis et al., 2019; Hinsley et al., 2017; Ibbett et al., 2019). We urge researchers to explore other options for reducing biases, but caution that they should ideally have a fundamental understanding of the sensitive behavior and the system it's in, before plunging into use of an SQT. Moreover, we caution overt reliance on complex statistical techniques, particularly models, without adequate interrogation of the assumptions and structure (e.g. Mac Nally, 2000). Finally, where possible, we suggest that simple measures of assessing internal consistency should be applied (Chuang et al., 2019).

Although there is no perfect SQT, we believe that understanding sensitive behaviors is highly important. Despite the hurdles intrinsic in obtaining an accurate estimation of behavior, we believe that the diversity of SQTs indicates that the use of them should be achievable for any researcher in conservation, regardless of sample size or funds. The use of them must be careful and thoughtful; however, the resulting reward of a more complete understanding of the complex and obscure counterbalance the effort involved in ensuring SQT efficacy.

\section{Author contribution}

All authors contributed equally to the manuscript.

\section{Funding}

There is no funding to report for this manuscript.

\section{Availability of data and material}

Not applicable.

\section{Code availability}

Not applicable.

\section{Declaration of competing interest}

There are no conflicts of interest in this manuscript.

\section{Acknowledgements}

We thank the two anonymous reviewers for their feedback, and to E. Moran for support in writing this paper.

\section{References}

Arnab, R., Rueda, M., 2016. Optional randomized response: a critical review. Handbook of Statistics. 34, 253-271. https://doi.org/10.1016/bs.host.2016.01.014.

Auspurg, K., Hinz, T., 2014. Factorial Survey Experiments, 1st ed. Sage Publications, Thousand Oaks, CA. 
Baruh, L., Secinti, E., Cemalcilar, Z., 2017. Online privacy concerns and privacy management: a meta-analytical review. J. Commun. 67, 26-53. https://doi.org/ 10.1111/jcom.12276.

Bennett, N.J., Roth, R., Klain, S.C., Chan, K., Christie, P., Clark, D.A., Cullman, G., Curran, D., Durbin, T.J., Epstein, G., Greenberg, A., Nelso, M.P., Sandlons, J., Stedman, R., Teel, T.L., Thomas, R., Veríssimo, D., Wyborn, C., 2017. Conservation social science: understanding and integrating human dimensions to improve conservation. Biol. Conserv. 205, 93-108. https://doi.org/10.1016/j. biocon.2016.10.006.

Blair, G., Imai, K., 2012. Statistical analysis of list experiments. Polit. Anal. 20, 47-77. https://doi.org/10.1093/pan/mpr048.

Blair, G., Imai, K., Lyall, J., 2014. Comparing and combining list and endorsement experiments: evidence from Afghanistan. Am. J. Polit. Sci. 58, 1043-1063. https:// doi.org/10.1111/ajps.12086.

Blair, G., Imai, K., Zhou, Y.Y., 2015. Design and analysis of the randomized response technique. J. Am. Stat. Assoc. 110, 1304-1319. https://doi.org/10.1080/ 01621459.2015.1050028.

Bornmann, L., Mutz, R., 2015. Growth rates of modern science: a bibliometric analysis based on the number of publications and cited references. J. Assoc. Inf. Sci. Tech. 66, 2215-2222. https://doi.org/10.1002/asi.23329.

Boruch, R.F., 1971. Assuring confidentiality of responses in social research: a note on strategies. American Sociol. 6, 308-311.

Bova, C.S., Aswani, S., Farthing, M.W., Potts, W.M., 2018. Limitations of the random response technique and a call to implement the ballot box method for estimating recreational angler compliance using surveys. Fish. Res. 208, 34-41. https://doi. org/10.1016/j.fishres.2018.06.017.

Brittain, S., Ibbett, H., de Lange, E., Dorward, L., Hoyte, S., Marino, A., MilnerGulland, J., Newth, J., Rakotonarivo, S., Veríssimo, D., Lewis, J., 2020. Ethical considerations when conservation research involves people. Conserv. Biol. 34, 925-933. https://doi.org/10.1111/cobi.13464.

Camilotti, G., 2016. Interventions to stop female genital cutting and the evolution of the custom: evidence on age at cutting in Senegal. J. Afr. Econ. 25, 133-158. https://doi. org/10.1093/jae/ejv013.

Cao, M., Breidt, F.J., Solomon, J.N., Conteh, A., Gavin, M.C., 2018. Understanding the drivers of sensitive behavior using Poisson regression from quantitative randomized response technique data. PLoS One 13, e0204433. https://doi.org/10.1371/journal. pone.0204433.

Cerri, J., Mori, E., Vivarelli, M., Zaccaroni, M., 2017. Are wildlife value orientations useful tools to explain tolerance and illegal killing of wildlife by farmers in response to crop damage? Eur. J. Wildl. Res. 63, 70. https://doi.org/10.1007/s10344-0171127-0.

Cerri, J., Ciappelli, A., Lenuzza, A., Zaccaroni, M., Nocita, A., 2018a. Recreational angling as a vector of freshwater invasions in Central Italy: perceptions and prevalence of illegal fish restocking. Knowl. Manag. Aquatic. Ec. 38 https://doi.org/ $10.1051 / \mathrm{kmae} / 2018028$.

Cerri, J., Scuffi, L., Nocita, A., Zaccaroni, M., Lenuzza, A., Cruyff, M., 2018b. Characterizing noncompliance in conservation: a multidimensional Randomized Response Technique for multinomial responses. BioRxiv 453159. https://doi.org/ 10.1101/453159.

Chang, C.H., Cruyff, M.J., Giam, X., 2018. Examining conservation compliance with randomized response technique analyses. Conserv. Biol. 32, 1448-1456. https://doi org/10.1111/cobi.13133.

Chhabra, A., Dass, B.K., Gupta, S., 2016. Estimating prevalence of sexual abuse by an acquaintance with an optional unrelated question RRT model. The North Carolina Journal of Mathematics and Statistics 2, 1-9.

Chuang, E., Dupas, P., Huillery, E., Seban, J., 2019. Sex, Lies, and Measurement: Do Indirect Response Survey Methods Work. Working Paper. https://web.stanford. edu/ pdupas/CDHS_measurement.pdf.

Cialdini, R.B., Demaine, L.J., Sagarin, B.J., Barrett, D.W., Rhoads, K., Winter, P.L., 2006. Managing social norms for persuasive impact. Soc. Influ. 1, 3-15. https://doi.org/ 10.1080/15534510500181459.

Clark, S.J., Desharnais, R.A., 1998. Honest answers to embarrassing questions: detecting cheating in the randomized response model. Psychol. Methods 3, 160. https://doi. org/10.1037/1082-989X.3.2.160.

Cruyff, M.J., Böckenholt, U., van der Heijden, P.G., 2016a. The multidimensional randomized response design: estimating different aspects of the same sensitive behavior. Behav. Res. Methods 48, 390-399. https://doi.org/10.3758/s13428-0150583-2.

Cruyff, M.J., Böckenholt, U., Van Der Heijden, P.G., Frank, L.E., 2016b. A review of regression procedures for randomized response data, including univariate and multivariate logistic regression, the proportional odds model and item response model, and self-protective responses. Handbook of Statistics 34, 287-315. https:// doi.org/10.1016/bs.host.2016.01.016.

Davis, E.O., Glikman, J.A., 2020. An assessment of wildlife use by Northern Laos nationals. Animals 10, 685. https://doi.org/10.3390/ani10040685.

Davis, E.O., Crudge, B., Lim, T., O’Connor, D., Roth, V., Hunt, M., Glikman, J.A., 2019. Understanding the prevalence of bear part consumption in Cambodia: a comparison of specialised questioning techniques. PLoS One 14, e0211544. https://doi.org/ 10.1371/journal.pone.0211544.

Davis, E.O., Veríssimo, D., Crudge, B., Lim, T., Roth, V., Glikman, J.A., 2020a. Insights for reducing the consumption of wildlife: the use of bear bile and gallbladder in Cambodia. People. Nat. 2, 950-963. https://doi.org/10.1002/pan3.10164.

Davis, E. O., Willemsen, M., Dang, V., O'Connor, D., Glikman, J. A, 2020b, An updated analysis of the consumption of tiger products in urban Vietnam. Glob. Ecol. Conserv., 22, e00960. doi:https://doi.org/10.1016/j.gecco.2020.e00960.
Droitcour, J. A., Larson, E. M., 2002. An innovative technique for asking sensitive questions: The three-card method. Bull. Sociol. Methodol. 75, 5-23. doi: $10.1177 \%$ 2F075910630207500103.

Droitcour, J., Caspar, R.A., Hubbard, M.L., Parsley, T.L., Visscher, W., Ezzati, T.M., 2004. The item count technique as a method of indirect questioning: a review of its development and a case study application. Wiley S. Pro. 185-210. https://doi.org/ 10.1002/9781118150382.ch11.

Eichhorn, B.H., Hayre, L.S., 1983. Scrambled randomized response methods for obtaining sensitive quantitative data. J. Stat. Plan. Infer. 7, 307-316. https://doi. org/10.1016/0378-3758(83)90002-2.

Esponda, F., Guerrero, V.M., 2009. Surveys with negative questions for sensitive items. Stat. Probabil. Lett. 79, 2456-2461. https://doi.org/10.1016/j.spl.2009.08.019.

Gaia, A., Al Baghal, T., 2019. The Longitudinal Item Count Technique: a new technique for asking sensitive questions in surveys. Methods, data, analyses: a journal for quantitative methods and survey methodology (mda) 13, 111-137. doi:10.12758/ mda.2018.09.

Gino, F., Ariely, D., 2016. Dishonesty explained: what leads moral people to act immorally. The social psychology of good and evil 322-344. http://people.duke.ed $\mathrm{u} / \sim$ dandan/webfiles/PapersDisHonesty/Dishonesty\%20Explained\%20What.doc.

Glynn, A.N., 2013. What can we learn with statistical truth serum? Design and analysis of the list experiment. Public. Opin. Quart. 77, 159-172. https://doi.org/10.1093/poq/ nfs070c.

Greenberg, B.G., Abul-Ela, A.L.A., Simmons, W.R., Horvitz, D.G., 1969. The unrelated question randomized response model: theoretical framework. J. Am. Stat. Assoc. 64, 520-539. https://doi.org/10.1080/01621459.1969.10500991.

Gregson, S., Zhuwau, T., Ndlovu, J., Nyamukapa, C.A., 2002. Methods to reduce social desirability bias in sex surveys in low-development settings: experience in Zimbabwe. Sex. Transm. Dis. 29, 568-575. https://doi.org/10.1097/00007435200210000-00002.

Griffiths, S., Lynch, T., Lyle, J., Wotherspoon, S., Wong, L., Devine, C., Pollock, K., Sawynok, W., Donovan, A., Fischer, M., Tickell, S., Moeseneder, C., 2017. Trial and Validation of Respondent-driven Sampling as a Cost-effective Method for Obtaining Representative Catch, Effort, Social and Economic Data From Recreational Fisheries. http://www.frdc.com.au/Archived-Reports/FRDC\%20Projects/2012-021-DLD.pdf.

Groenitz, H., 2014. A new privacy-protecting survey design for multichotomous sensitive variables. Metrika 77, 211-224. https://doi.org/10.1007/s00184-012-0406-8.

Heck, D.W., Hoffmann, A., Moshagen, M., 2018. Detecting nonadherence without loss in efficiency: a simple extension of the crosswise model. Behav. Res. Methods 50, 1895-1905. https://doi.org/10.3758/s13428-017-0957-8.

Hinsley, A., Verissimo, D., Roberts, D.L., 2015. Heterogeneity in consumer preferences for orchids in international trade and the potential for the use of market research methods to study demand for wildlife. Biol. Conserv. 190, 80-86. https://doi.org/ 10.1016/j.biocon.2015.05.010.

Hinsley, A., Nuno, A., Ridout, M., St. John, F.A., Roberts, D.L., 2017. Estimating the extent of CITES noncompliance among traders and end-consumers; lessons from the global orchid trade. Conserv. Lett. 10, 602-609. https://doi.org/10.1111/ conl.12316.

Hinsley, A., Keane, A., St. John, F.A., Ibbett, H., Nuno, A., 2019. Asking sensitive questions using the unmatched count technique: applications and guidelines for conservation. Methods Ecol. Evol. 10, 308-319. https://doi.org/10.1111/2041. 210X.13137.

Hoffmann, A., Diedenhofen, B., Verschuere, B., Musch, J., 2015. A strong validation of the crosswise model using experimentally-induced cheating behavior. Exp. Psychol. 62, 403-414. https://doi.org/10.1027/1618-3169/a000304.

Hoffmann, A., De Puiseau, B.W., Schmidt, A.F., Musch, J., 2017. On the comprehensibility and perceived privacy protection of indirect questioning techniques. Behav. Res. Methods 49, 1470-1483. https://doi.org/10.3758/s13428016-0804-3.

Hoffmann, A., Meisters, J., Musch, J., 2020. On the validity of non-randomized response techniques: an experimental comparison of the crosswise model and the triangular model. Behav. Res. Methods 1-15. https://doi.org/10.3758/s13428-020-01349-9.

Höglinger, M., Diekmann, A., 2017. Uncovering a blind spot in sensitive question research: false positives undermine the crosswise-model RRT. Polit. Anal. 25, 131-137. https://doi.org/10.1017/pan.2016.5.

Ibbett, H., Lay, C., Phlai, P., Song, D., Hong, C., Mahood, S.P., Milner-Gulland, E.J., 2019. Conserving a globally threatened species in a semi-natural, agrarian landscape. Oryx. 53, 181-191. https://doi.org/10.1017/S0030605316001708.

Jerke, J., Johann, D., Rauhut, H., Thomas, K., 2019. Too sophisticated even for highly educated survey respondents? A qualitative assessment of indirect question formats for sensitive questions. Surv. Res. Methods-Ger 13, 319-351. doi:10.18148/srm/ 2019.v13i3.7453.

Jones, S., Papworth, S., Keane, A.M., Vickery, J., St John, F.A., 2020. The bean method as a tool to measure sensitive behaviour. Conserv. Biol. https://doi.org/10.1111/ cobi.13607.

Korndörfer, M., Krumpal, I., Schmukle, S.C., 2014. Measuring and explaining tax evasion: improving self-reports using the crosswise model. J. Econ. Psychol. 45, 18-32. https://doi.org/10.1016/j.joep.2014.08.001.

Krumpal, I., 2013. Determinants of social desirability bias in sensitive surveys: a literature review. Qual. Quant. 47, 2025-2047. https://doi.org/10.1007/s11135011-9640-9.

Krumpal, I., Jann, B., Korndörfer, M., Schmukle, S. 2018. Item sum double-list technique: An enhanced design for asking quantitative sensitive questions. Surv. Res. Methods Ger. 12, 91-102. doi:10.18148/srm/2018.v12i2.7247.

Kuk, A.Y., 1990. Asking sensitive questions indirectly. Biometrika. 77, 436-438. https:// doi.org/10.1093/biomet/77.2.436. 
Lagerås, A., Lindholm, M., 2020. How to ask sensitive multiple-choice questions. Scand. J. Stat. 47, 397-424. https://doi.org/10.1111/sjos.12411.

Lau, J.T., Yeung, N.C., Mui, L.W., Tsui, H.Y., Gu, J., 2011. A simple new method to triangulate self-reported risk behavior data-the bean method. Sex. Transm. Dis. 38, 788-792. https://doi.org/10.1097/OLO.0b013e318218cc66.

Lee, S.M., Peng, T.C., Tapsoba, J.D.D., Hsieh, S.H., 2017. Improved estimation methods for unrelated question randomized response techniques. Commun. Stat. A. - Theor. 46, 8101-8112. https://doi.org/10.1080/03610926.2016.1175626.

Liu, Y., Tian, G.L., Wu, Q., Tang, M.L., 2019. Poisson-Poisson item count techniques for surveys with sensitive discrete quantitative data. Stat. Pap. 60, 1763-1791. https:// doi.org/10.1007/s00362-017-0895-7.

Mac Nally, R., 2000. Regression and model-building in conservation biology, biogeography and ecology: the distinction between-and reconciliation of'predictive' and 'explanatory' models. Biodivers. Conserv. 9, 655-671. https://doi. org/10.1023/A:1008985925162.

Meisters, J., Hoffmann, A., Musch, J., 2020. Can detailed instructions and comprehension checks increase the validity of crosswise model estimates? PLoS One 15, e0235403. https://doi.org/10.1371/journal.pone.0235403.

Miller, J.D., 1985. The nominative technique: a new method of estimating heroin prevalence. NIDA Res. Monogr. 54, 104-124.

Munn, Z., Peters, M.D., Stern, C., Tufanaru, C., McArthur, A., Aromataris, E., 2018. Systematic review or scoping review? Guidance for authors when choosing between a systematic or scoping review approach. BMC Med. Res. Methodol. 18, 1-7. https:// doi.org/10.1186/s12874-018-0611-x.

Navarro, D.J., 2019. Between the devil and the deep blue sea: tensions between scientific judgement and statistical model selection. Comput. Brain. Behav. 2, 28-34. https:// doi.org/10.1007/s42113-018-0019-z.

Nuno, A., St John, F.A., 2015. How to ask sensitive questions in conservation: a review of specialized questioning techniques. Biol. Conserv. 189, 5-15. https://doi.org/ 10.1016/j.biocon.2014.09.047.

Nuno, A., Bunnefeld, N., Naiman, L.C., Milner-Gullan, E.J., 2013. A novel approach to assessing the prevalence and drivers of illegal bushmeat hunting in the Serengeti. Conserv. Biol. 27, 1355-1365. https://doi.org/10.1111/cobi.12124.

Perri, P.F., Rodríguez, B.C., García, M.D.M.R., 2018. A mixed-mode sensitive research on cannabis use and sexual addiction: improving self-reporting by means of indirect questioning techniques. Qual. Quant. 52, 1593-1611. https://doi.org/10.1007/ s11135-017-0537-0.

Petróczi, A., Nepusz, T., Cross, P., Taft, H., Shah, S., Deshmukh, N., Schaffer, J., Shane, M., Adesanwo, C., Barker, J., Naughton, D.P., 2011. New non-randomised model to assess the prevalence of discriminating behaviour: a pilot study on mephedrone. Subst. Abuse. Treat. Pr. 6, 20. https://doi.org/10.1186/1747-597X-620.

Pollock, K.H., Bek, Y., 1976. A comparison of three randomized response models for quantitative data. J. Am. Stat. Assoc. 71, 884-886.

Raghavarao, D., Federer, W.T., 1979. Block total response as an alternative to the randomized response method in surveys. J. R. Stat. Soc. B. 41, 40-45. https://doi. org/10.1111/j.2517-6161.1979.tb01055.x.

Rosenfeld, B., Imai, K., Shapiro, J.N., 2016. An empirical validation study of popular survey methodologies for sensitive questions. Am. J. Polit. Sci. 60, 783-802. https:// doi.org/10.1111/ajps.12205.

Russo, A, Strazzari, F., 2020. The politics of safe research in violent and illiberal contexts. Bliesemann de Guevara B, Bøås M (Eds.), Doing Fieldwork in Areas of International Intervention: A Guide to Research in Violent and Closed Contexts (pp. 75-94). 75. Bristol, UK: Bristol University Press.

Santangeli, A., Arkumarev, V., Rust, N., Girardello, M., 2016. Understanding, quantifying and mapping the use of poison by commercial farmers in Namibia-implications for scavengers' conservation and ecosystem health. Biol. Conserv. 204, 205-211. https://doi.org/10.1016/j.biocon.2016.10.018.

Schröter, H., Studzinski, B., Dietz, P., Ulrich, R., Striegel, H., Simon, P., 2016. A comparison of the cheater detection and the unrelated question models: a randomized response survey on physical and cognitive doping in recreational triathletes. PLoS One 11, e0155765. https://doi.org/10.1371/journal. pone. 0155765.

Solomon, J., Jacobson, S.K., Wald, K.D., Gavin, M., 2007. Estimating illegal resource use at a Ugandan park with the randomized response technique. Hum. Dim. Wildl. 12, 75-88. https://doi.org/10.1080/10871200701195365.

Solomon, J.N., Gavin, M.C., Gore, M.L., 2015. Detecting and understanding noncompliance with conservation rules. Biol. Conserv. 189, 1-4. https://doi.org/ 10.1016/j.biocon.2015.04.028.

St. John, F.A., Edwards-Jones, G., Gibbons, J.M., Jones, J.P., 2010. Testing novel methods for assessing rule breaking in conservation. Biol. Conserv. 143, 1025-1030. https://doi.org/10.1016/j.biocon.2010.01.018.

St. John, F.A., Mai, C.H., Pei, K.J.C., 2015. Evaluating deterrents of illegal behaviour in conservation: carnivore killing in rural Taiwan. Biol. Conserv. 189, 86-94. https:// doi.org/10.1016/j.biocon.2014.08.019.

St. John, F., Brockington, D., Bunnefeld, N., Duffy, R., Homewood, K., Jones, J. P., Keane, A. P., Milner-Gulland, E. J., Nuno, A., Razafimanahaka, J., 2016. Research ethics: Assuring anonymity at the individual level may not be sufficient to protect research participants from harm. Biol. Conserv. 100, 208-209. doi:10.1016\%2Fj. biocon.2016.01.025.

St. John, F.A., Linkie, M., Martyr, D.J., Milliyanawati, B., McKay, J.E., Mangunjaya, F.M., Leader-Williams, N., Struebig, M.J., 2018. Intention to kill: tolerance and illegal persecution of Sumatran tigers and sympatric species. Conserv. Lett. 11, e12451 https://doi.org/10.1111/conl.12451.

Tian, G.L., 2014. A new non-randomized response model: the parallel model. Stat. Neerl. 68, 293-323. https://doi.org/10.1111/stan.12034.

Tian, G.L., Yu, J.W., Tang, M.L., Geng, Z., 2007. A new non-randomized model for analysing sensitive questions with binary outcomes. Stat. Med. 26, 4238-4252. https://doi.org/10.1002/sim.2863.

Tian, G. L., Tang, M. L., Wu, Q., Liu, Y., 2017. Poisson and negative binomial item count techniques for surveys with sensitive question. Stat. Methods Med. Res. 26, 931-947. doi:10.1177\%2F0962280214563345.

Tian, G.L., Liu, Y., Tang, M.L., 2019. Logistic regression analysis of non-randomized response data collected by the parallel model in sensitive surveys. Aust. NZ. J. Stat. 61, 134-151. https://doi.org/10.1111/anzs.12258.

Trappmann, M., Krumpal, I., Kirchner, A., Jann, B., 2014. Item sum: a new technique for asking quantitative sensitive questions. J. Surv. Stat. Method. 2, 58-77. https://doi. org/10.1093/jssam/smt019.

Tu, S.H., Hsieh, S.H., 2017. Estimates of lifetime extradyadic sex using a hybrid of randomized response technique and crosswise design. Arch. Sex. Behav. 46, 373-384. https://doi.org/10.1007/s10508-016-0740-4.

Veríssimo, D., Vieira, S., Monteiro, D., Hancock, J., Nuno, A., 2020. Audience research as a cornerstone of demand management interventions for illegal wildlife products: demarketing sea turtle meat and eggs. Conserv. Sci. Pract. 2, e164 https://doi.org/ 10.1111/csp2.164.

van Vliet, N., Nebesse, C., Nasi, R., 2015. Bushmeat consumption among rural and urban children from province Orientale, Democratic Republic of Congo. Oryx. 49, 165-174. https://doi.org/10.1017/S0030605313000549.

Warner, S.L., 1965. Randomized response: a survey technique for eliminating evasive answer bias. J. Am. Stat. Assoc. 60, 63-69.

Wolter, F., 2019. A New Version of the Item Count Technique for Asking Sensitive Questions: Testing the Performance of the Person Count Technique. Methods, data, analyses: a journal for quantitative methods and survey methodology (mda). 13, 169-192. doi:10.12758/mda.2018.04.

Wu, Q., Tang, M. L., 2016. Non-randomized response model for sensitive survey with noncompliance. Stat. Methods Med. Res. 25, 2827-2839. doi:10.1177\% 2F0962280214533022.

Yu, J.W., Tian, G.L., Tang, M.L., 2008. Two new models for survey sampling with sensitive characteristic: design and analysis. Metrika. 67, 251. https://doi.org/ 10.1007/s00184-007-0131-x. 